Review Article

\title{
Delayed Eruption of Permanent Dentition and Maxillary Contraction in Patients with Cleidocranial Dysplasia: Review and Report of a Family
}

\author{
A. Impellizzeri $\left(\mathbb{D},{ }^{1}\right.$ G. Midulla, ${ }^{2,3}$ U. Romeo $\left(\mathbb{D},{ }^{1}\right.$ C. La Monaca, ${ }^{1}$ E. Barbato, ${ }^{1}$ \\ and G. Galluccio ${ }^{1}{ }^{1}$ \\ ${ }^{1}$ Department of Oral and Maxillofacial Sciences, Sapienza University of Rome, Rome, Italy \\ ${ }^{2}$ Private Practice, Rome, Italy \\ ${ }^{3}$ Private Practice, Montreux, Switzerland
}

Correspondence should be addressed to G. Galluccio; gabriella.galluccio@uniroma1.it

Received 12 February 2018; Accepted 20 May 2018; Published 4 July 2018

Academic Editor: Carla Evans

Copyright ( 2018 A. Impellizzeri et al. This is an open access article distributed under the Creative Commons Attribution License, which permits unrestricted use, distribution, and reproduction in any medium, provided the original work is properly cited.

Introduction. Cleidocranial dysplasia (CCD) is an inherited disease caused by mutations in the RUNX2 gene on chromosome $6 \mathrm{p} 21$. This pathology, autosomal dominant or caused by a spontaneous genetic mutation, is present in one in one million individuals, with complete penetrance and widely variable expressivity. Aim. To identify the incidence of these clinical findings in the report of the literature by means of PubMed interface from 2002 to 2015, with the related keywords. The report of local patients presents a clinical example, related to the therapeutic approach. Results and Discussions. The PubMed research resulted in 122 articles. All the typical signs were reported in all presented cases. The maxilla was hypoplastic in $94 \%$ of the patients. Missing of permanent teeth was found in two cases: one case presented a class II jaw relationship, instead of class III malocclusion. Similar findings were present in our cohort. Conclusion. CCD is challenging for both the dental team and the patient. The treatment requires a multidisciplinary approach. Further studies are required to better understand the cause of this disease. According to this review, a multistep approach enhances the possibilities to achieve the recovery of the most possible number of teeth, as such to obtain a good occlusion and a better aesthetic.

\section{Introduction}

Cleidocranial dysplasia (CCD) was first described by Pierre Marie and Paul Sainton in 1898 as "dysostose cléido-crânienne héréditaire," mutational dysostosis, or cleidocranial dysostosis. Though the first description of cleidocranial dysostosis is credited to Meckle in 1760, the combination of clavicular and cranial defects was identified by Scheuthauer in 1871 .

CCD is an autosomal dominant inherited disease caused by mutations in the RUNX2 gene on chromosome $6 \mathrm{p} 21$ encoding a transcription factor involved in osteoblast differentiation and skeletal morphogenesis. This pathology is transmitted as an autosomal dominant trait or it is caused by a spontaneous genetic mutation and is present at a frequency of one in one million individuals. It presents complete penetrance and widely variable expressivity.
The term "cleidocranial dysostosis" has been used; however, the syndrome got renamed aptly from cleidocranial dysostosis to cleidocranial dysplasia after the conference for constitutional disorders of bone held in Paris in 1969, given that RUNX2 has important functions both during skeletal formation and in bone maintenance, and CCD is affecting not only the clavicles and the skull but the entire skeleton $[1,2]$.

This rare disease is classified as \#119600. A number sign (\#) is used with this entry because of evidence that CCD is caused by heterozygous loss-of-function mutation in the RUNX2 gene (600211), encoding transcription factor CBFA1. Heterozygous duplication in RUNX2 resulting in a gain of function causes metaphyseal dysplasia and maxillary hypoplasia with or without brachydactyly (MDMHB; 156510). Pycnodysostosis (265800) and mandibuloacral dysplasia (248370) are disorders to be considered in the 
differential diagnosis of CCD. Acroosteolysis and bone sclerosis with tendency to fracture are differentiating features of pycnodysostosis.

Many case reports and case studies have been reported in the literature [3-7]. One of the most colorful families was described by Jackson [8]. The condition occurred in many descendants of a Chinese man named Arnold who embraced the Mohammedan religion and 7 wives in South Africa. Jackson in 1951 was able to trace 356 descendants, of whom 70 were affected by the "Arnold head" $[8,9]$.

Due to the wide variability, diagnosis solely based on the clinical features may be difficult. CCD is mainly characterized by a pathognomonic deformity of the skull (persistently open skull sutures with bulging calvaria), hypoplastic midface, lack of eruption of permanent teeth, supernumerary teeth, hypoplastic or aplastic clavicles, and multiple other malformations [10]. CCD makes also a special problem for the dentists due to a large number of abnormalities: highly arched palate, cleft palate, delayed union of mandibular symphysis, delayed tooth eruption, dental root and crown abnormalities, crypt formation around impacted teeth, and ectopic teeth. Dental abnormalities are sometimes a sole clinical sign of the mutation.

Early diagnosis of CCD is essential for introduction of an appropriate treatment approach based on interdisciplinary cooperation between orthodontists as well as oral and maxillofacial surgeons and general dentists at the right moment [11].

The main clinical features of CCD include persistently open skull sutures with bulging calvaria, hypoplasia, or aplasia of the clavicles permitting abnormal facility in opposing the shoulders, wide pubic symphysis, short middle phalanx of the fifth fingers, dental anomalies, and often vertebral malformation (Table 1 ).

Cooper et al. in 2001 assembled a series of 90 CCD individuals and 56 relative controls ascertained from genetic and dental practices in the United States, Canada, Europe, and Australia. A number of previously unrecognized complications were significantly increased, including scoliosis, pes planus, sinus infections, upper respiratory complications, recurrent otitis media, and hearing loss [12].

Dental abnormalities, including supernumerary teeth, failure of exfoliation of the primary dentition, and malocclusion, were found to be serious and complex problems that required intervention. The combination of normal deciduous teeth, delayed eruption of permanent teeth, and multiple impacted supernumerary teeth is practically diagnostic of CCD.

The increase in odontogenesis leads to excessive number of supernumerary teeth. A study by Yamamota et al. concluded that an early loss of gubernacular cords resulted in failure of a tooth to erupt [13].

As stated by Roberts et al. in 2013, "the supernumerary teeth in CCD may result from the lack of inhibition or incomplete resorption of tooth bud formation. Supernumerary teeth may also result from the presence of remnants of dental laminae following dental extraction. These epithelial cell rests are usually resorbed during the normal tooth morphogenesis" [9].
It has been argued that CBFA1 mutations segregate with the CCD phenotype and that heterozygous loss of function is sufficient to produce the characteristic clinical findings. The CBFA1, a subunit of the core binding factor (CBF) transcription factors, probably plays a significant role in bone development, as it has been revealed by mutated mice in which the Cbfa1 was completely deficient and died immediately after birth owing to a complete absence of bone. The cause was identified in an arrest in endochondral as well as membranous bone formation. Moreover, the stimulation of cells that normally do not express Cbfa1 with BMP7 (a secreted molecule that can induce bone formation) leads to expression of $C b f a 1$ before the expression of any other osteoblast marker genes identifying $C b f a 1$ as an inducer of osteoblast differentiation (Figure 1).

Very recent findings suggest that $C b f a 1$ is not only essential for osteoblast formation, but also a major regulator of chondrocyte differentiation. In Cbfa1 (-/-) mice chondrocytes, hypertrophy within this cartilaginous model does not take place, indicating a role for $C b f a 1$. In addition, also vascular invasion of calcified cartilage does not take place [12].

Throughout the years, different clinical approaches for the treatment of patients with CCD have been suggested in the literature $[13,14]$.

(1) The Toronto-Melbourne approach is based on timed, serial extractions of deciduous teeth; it depends on the extent to which the roots of the permanent teeth have developed, so for this approach, the best period for treatment is in the initial stages with a combined oral surgery and orthodontic approach. It is recommended that surgical procedures should begin at about 5 to 6 years of age with extraction of the anterior deciduous teeth (Table 2). Later (6 or 7 years of age), the deciduous incisors are exposed, and healing is allowed; orthodontic brackets are placed on the permanent incisors as soon as possible, and the deciduous posterior teeth are extracted. When the patient is 9 or 10 years of age, the permanent premolars are exposed and allowed to heal. Thereafter, orthodontic brackets are placed on the permanent canines and premolars. During each procedure, which is performed under general anesthesia, the supernumerary teeth are also removed together with the bone covering the underlying permanent teeth.

(2) The Belfast-Hamburg approach is a single surgical approach that limits the number of surgeries to a single episode. All deciduous and supernumerary teeth are extracted, and all unerupted permanent teeth are exposed simultaneously under general anesthesia. Surgical packing is placed, and healing occurs by secondary intention. The surgical packs are changed frequently until brackets can be bonded into place. Orthodontic appliances are placed on the few fully erupted teeth, and elastics are tied to the unerupted teeth to encourage eruption (Table 3). 
TABLE 1

Clinical findings

(i) Open fontanelle or delayed closure of fontanelle

(ii) Open sutures

(iii) Wormian bones

(iv) Skull: usually large broad and brachycephalic type

(v) Hypoplasia of maxillae, lacrimal, nasal, and zygomatic

bones; discontinuous zygomatic arch; parallel-sided ascending ramus of the mandible; upwards and/or posteriorly pointing coronoid process with less thick masseter muscles than in the age- and sex-matched control subjects

(vi) Underdeveloped and narrow paranasal sinuses

(vii) Prominent frontal, parietal, and occipital bones

(viii) Ocular hypertelorism and a mild exophthalmus

(ix) Small and bell-shaped thoracic cage with short, oblique ribs

(x) Hypoplastic scapulae with deficiencies in the supraspinatus fossae and acromial facets

(xi) Defects of the vertebral column: scoliosis and kyphosis

(xii) Pelvis: widened pubis symphysis due to a delay in ossification during adulthood. Hypoplasia and anterior rotation of the iliac wings and wide sacroiliac joints; large femoral epiphyses, broad femoral necks, and frequently coxa vara. Caesarean section of the dysplastic pelvis often necessitates in the pregnant female

(xiii) Presence of both proximal and distal epiphyses in the second metacarpals and metatarsals leading to excessive growth and length

(xiv) Unusually short bones of the hands and feet, especially the distal phalanges and the middle phalanges of the second and fifth fingers

(xv) Cone-shaped epiphyses and premature closure of epiphyseal growth plates lead to shortening of other bones. Tapered appearance to the digit, hypoplastic or dysplastic nails, sometimes absent

(xvi) Anomalous muscles secondary to bony involvement
Dentoalveolar characteristics

(i) Over retained deciduous teeth without any resorption in roots

(ii) Delayed/retarded eruption of permanent teeth because of lessened eruptive potential, although it is not entirely absent

(iii) Multiple impacted supernumerary teeth that displace the developing permanent teeth and obstruct their eruption, as a possible result of incomplete or delayed resorption of the dental lamina, which is reactivated at the time of crown completion of the normal permanent dentition

(iv) Crypt formation around impacted and ectopic teeth

(v) High narrow arched palate and infrequently cleft palate

(vi) Partial anodontia

(vii) Reduced height of the lower third of the face and a skeletal class III tendency due to the

underdevelopment of the maxilla and to an upward and forward mandibular rotation. Markedly reduced vertical development of the alveolar bone, with a shallow buccal and lingual sulcus

(viii) Possible nonunion of the symphysis of the mandible

(ix) Late but spontaneous eruption of first and usually second permanent molars in both the jaws

(x) Delay in the root development of permanent teeth and short and thinner roots

(xi) Absence or lack of cellular cementum on the roots of the permanent teeth with no increased thickening of primary acellular cementum, probably due to mechanical resistance to eruption by the dense alveolar bone overlying the unerupted teeth

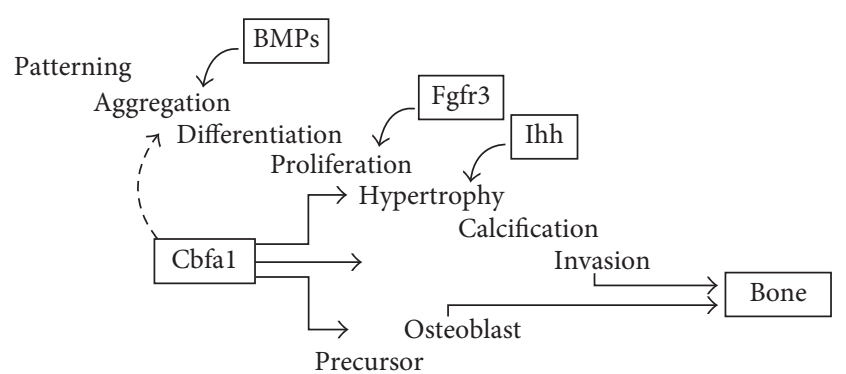

Figure 1: Role of Cbfa1 in bone formation (from [10]).

(3) The Jerusalem approach is based on at least 2 surgical interventions, depending on the root development of the permanent dentition. In the first phase, which begins approximately at 10 to 12 years of age, the anterior teeth are involved in the treatment in phase 2 (age 13 years and older), and the posterior teeth are treated. These stages are carried out simultaneously in both jaws under general anesthesia. One of the goals of this approach is to immediately deal with the absence of anterior teeth by placing an orthodontic appliance to erupt the anterior teeth first (Table 4).

(4) The "Bronx Approach" uses an interim overdenture prosthesis during the long course of treatment [15]. The timing of the surgical intervention is dependent on the root development of the permanent teeth (Table 5).

1.1. Aim of the Study. The aim of the study is to identify the incidence of delayed eruption of permanent teeth and other dentoalveolar findings, that is, supernumerary teeth, eruption failure, and hypoplastic upper jaw, on all clinical reports found on international literature by means of PubMed interface form January 2002 to December 2015. We investigated the incidence of high-arch palate and contraction of the upper jaw and the response to dentoalveolar or skeletal expansion using orthodontic appliances, such as TPA, Quadhelix, or REP. A local patient cohort with a family report of three patients has been analyzed, identifying most suitable treatment strategy. 
TABLE 2: Multiple surgery approach (Toronto-Melbourne).

\begin{tabular}{|c|c|}
\hline Stage 1 & Surgery \\
\hline 5 to 6 years & Extractions/deciduous incisors \\
\hline 9 to 10 years & $\begin{array}{c}\text { Extractions/deciduous posterior } \\
\text { teeth }\end{array}$ \\
\hline Stage 2 & Surgery/orthodontics \\
\hline $\begin{array}{l}\text { When first molars have been } \\
\text { banded }\end{array}$ & $\begin{array}{c}\text { Surgical exposure of permanent } \\
\text { incisors }\end{array}$ \\
\hline $\begin{array}{l}\text { Following healing from } \\
\text { previous surgical exposure }\end{array}$ & Brackets placed on incisors \\
\hline 9 to 12 years & $\begin{array}{l}\text { Surgical exposure of permanent } \\
\text { premolars/supernumerary teeth } \\
\text { removed }\end{array}$ \\
\hline $\begin{array}{l}\text { Following healing of previous } \\
\text { surgical exposure }\end{array}$ & $\begin{array}{c}\text { Brackets placed on premolars } \\
\text { and canines }\end{array}$ \\
\hline
\end{tabular}

Table 3: Single surgery approach (Belfast-Hamburg).

\begin{tabular}{c}
\hline Sntervention \\
\hline Extractions of all deciduous teeth and all \\
supernumerary teeth \\
Exposure of all permanent teeth \\
Brackets bonded immediately \\
Surgical flap closed \\
Orthodontic appliance bonded on fully erupted \\
teeth \\
Orthodontic elastic traction of all unerupted teeth
\end{tabular}

TABle 4: Two surgery approach (Jerusalem).

\begin{tabular}{lc}
\hline Intervention 1 & Surgery/orthodontics \\
\hline Dental age 7 to 8 & $\begin{array}{c}\text { Extractions/anterior deciduous teeth and all } \\
\text { supernumerary teeth } \\
\text { Brackets bonded immediately } \\
\text { Surgical flap closed }\end{array}$ \\
\hline Intervention 2 & Surgery/orthodontics \\
\hline Dental age 10 to & $\begin{array}{c}\text { Expostractions/remaining deciduous teeth } \\
\text { Brackets bonded immediately } \\
\text { Surgical flaps closed }\end{array}$ \\
\hline
\end{tabular}

TABLE 5: Surgical-prosthetic approach (Bronx).

\begin{tabular}{|c|c|}
\hline Surgery & Surgery \\
\hline Intervention 1 & $\begin{array}{l}\text { Extractions/deciduous teeth and } \\
\text { all supernumerary teeth } \\
\text { Surgical flaps closed }\end{array}$ \\
\hline Intervention 2 & $\begin{array}{l}\text { Exposure of unerupted teeth } \\
\text { Brackets bounded immediately } \\
\text { Surgical flaps closed }\end{array}$ \\
\hline Intervention 3 & $\begin{array}{l}\text { Le Fort I Osteotomy. Orthognatic surgery } \\
\text { Placement of dental implants }\end{array}$ \\
\hline
\end{tabular}

\section{Materials and Methods}

The study is divided into two sections: a systematic review of the literature and the description of a family of two patients and their mother with CCD observed in our Department of Orthodontics of "Sapienza"-University of Roma.

\subsection{Literature Review (LR)}

2.1.1. Inclusion and Exclusion Criteria. All case series and case reports on humans reporting description of clinical parameters in CCD-affected patients were included from January 2002 until December 2015. Grey literature was excluded. Only reports written in English, German, or French were included.

Papers that were primarily concerned with specific pathological findings or radiological modalities were not included. All reports that contained only genotype descriptions were excluded. Studies about prenatal diagnosis of CCD were not included in the LR.

2.1.2. Search Strategy. The PubMed interface of Medline (http://www.ncbi. nlm.nih.gov) was searched using the following key words: "Cleidocranial dysplasia," "Dysostose cléido-crânienne," "Cleidocranial dysostosis," and "Osteodental dysplasia."

The cases presented include literature reference, gender distribution, and patients' age at the time of presentation. Signs and symptoms were divided into the categories "supernumerary teeth," "failure of tooth eruption,' "delayed eruption of permanent teeth," "hypoplastic maxilla," "transversal contraction of the maxilla," "clavicular sign," and "other skeletal disorders." As described in the literature, the "clavicular sign" was defined by the patient's ability to oppose the shoulders in front as a result of hypoplastic or aplastic clavicles. The family history was also considered.

Furthermore, the aim was to investigate the answer of these patients to an orthopedic therapy using the rapid palate expander (REP), hypothesizing that most patients do not have a positive response to the device, needing surgicalassisted rapid palate expansion (SARPE) to correct the transversal discrepancies.

2.1.3. Local Patient Cohort. The clinical features of two siblings and their mother, all affected by CCD, who came to our department of Orthodontics at Sapienza University of Rome are described. The patients came to our observation after being treated by a general dentist without any successful therapy. Ortopanoramic and lateral cephalometric radiographs were prescribed as well as a TC cone-beam to evaluate dental and skeletal conditions. Moreover, a detailed anamnesis was collected to evidence the pedigree of the family. All medical files were also considered to picture a precise diagnosis of the two patients, including the growth stage and prediction to elaborate an accurate treatment planning.

This study was approved by the Department of Oral and Maxillofacial Sciences-Umberto I Hospital IRB, and all participants signed an informed consent agreement. 
TABLE 6

\begin{tabular}{lcc}
\hline & Reference & Rationale for exclusion \\
\hline 1 & Anthonappa et al. [17] & No dental findings, genetic analysis \\
2 & Takenouchi et al. [18] & No dental findings, patient with cognitive decline \\
3 & Rallan et al. [19] & Nonsyndromic case \\
4 & Wang and Neustein [20] & Nontal findings \\
5 & Matsushita et al. [21] & Age of case report (2-year-old boy) \\
6 & Broeks et al. [22] & Age of case report (infant) \\
7 & Gardham et al. [23] & Age of case report (infant) \\
8 & Northup at al. [24] & Age of case report (infant) \\
9 & Cardoso et al. [25] & Age of case report (infant) \\
10 & Shen et al. [26] & No dental findings \\
11 & Manjunath et al. [27] & No dental findings \\
12 & Pamuk et al. [28] & No dental findings \\
13 & Issever et al. [29] & No dental findings \\
14 & Pal et al. [30] & No dental findings \\
15 & Fernandes et al. [31] & No dental findings \\
16 & Cunningham et al. [32] & Age of case report (infant) \\
17 & Campos Junior et al. [33] & Age of case report (infant) \\
18 & Izumi et al. [34] & Age of case report (infant) \\
19 & Fernandez et al. [35] & No dental findings \\
20 & Goto et al. [36] & Age of case report (infant) \\
21 & Patel and Athavale [37] & Age of case report (infant) \\
22 & Golan et al. [38, 39] & same case already reported \\
23 & Sakai et al. [40] & Age of case report (75-year-old man)
\end{tabular}

\section{Results}

3.1. Genetics of CCD. Runx 2 is part of a transcription factor complex that directs the differentiation of mesenchymal precursor cells toward mature osteoblasts. Mutations of R225 are most frequently identified with many independent CCD patients reported to date. R225 resides within a scratch of basic amino acids at the carboxy terminus of the runt domain. This motif has been shown to act as a nuclear localization signal, and mutations affecting R225 inhibit the nuclear accumulation of Runx2 protein $[14,16]$.

Runx2 is expressed in an initial period of embryonic development; it plays a significant role in both chondrocyte and osteoblast lineages. Osteoblasts take part in new bone formation.

RUNX2 plays a significant role in the epithelial-mesenchymal interactions that control progressive tooth morphogenesis and histodifferentiation of the epithelial enamel organ.

\section{Literature Review}

The PubMed research resulted in 122 articles containing the keywords "Cleidocranial dysplasia," "Dysostose cléidocrânienne," "Cleidocranial dysostosis," and "Osteo-dental dysplasia." Among these 122 articles, 42 were excluded from the SR only by reading the title and the abstract, as they treated the following:

(i) Prenatal diagnosis of CCD (6 articles)

(ii) Neonates with CCD (4 articles)

(iii) Nonsyndromic conditions of patients presenting supernumerary teeth (8 articles)

(iv) Related syndromes presenting similar symptoms as CCD such as Yunis-Varón Syndrome OMIM
\#216340 (6 articles), Ehlers Danlos syndrome OMIM \#130000, Pycnodysostosis OMIM \#265800 (2 articles), anophthalmia syndrome OMIM \#206900 (1 article) other genetic mutations (4 articles)

(v) A cover picture was excluded from the LR

(vi) A quiz was also excluded from the LR

(vii) No full text available (9 papers).

After careful analysis of the remaining 80 full texts, it was possible to exclude further 23 papers for several reasons. Table 6 shows the articles excluded and the rationale for exclusion.

Three papers were specifically researched on the PubMed interface and included in the LR as perfectly matching the inclusion criteria. Finally, 60 were included in the SR as they reported the variables of interest (Table 7) (Figure 2).

Of all the variables reported, we analyzed those relative to the clinical signs of the syndrome and those related to the kind of treatment performed.

Among all the case reports analyzed, we can subdivide our population in two groups on the basis of gender (Table 8). The first group consists of 46 female patients with a mean age of 18.85 years. Supernumerary teeth were reported in all presented cases. There was an eruption failure and delayed eruption of permanent teeth in all cases as well. The maxilla was hypoplastic in $94 \%$ of the patients. Maxillary contraction and the clavicular sign were found in all the cases reported. Missing of permanent teeth was found in two cases: tooth 3.2 in one case and tooth 3.7 in the other case were missing.

Four patients were treated with orthognathic surgery for maxillary advancement. The contraction of the upper jaw 





International Journal of Dentistry

7






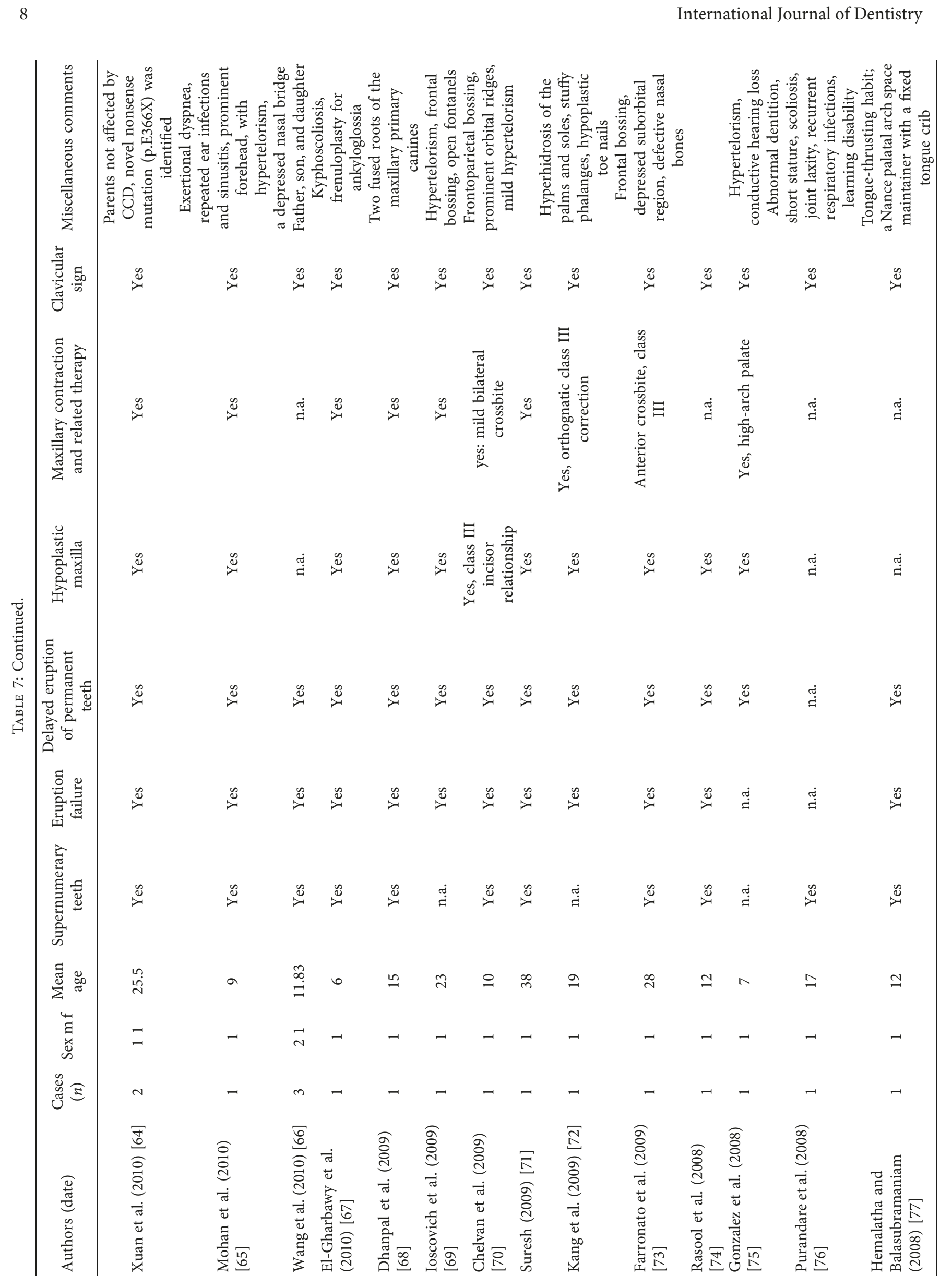




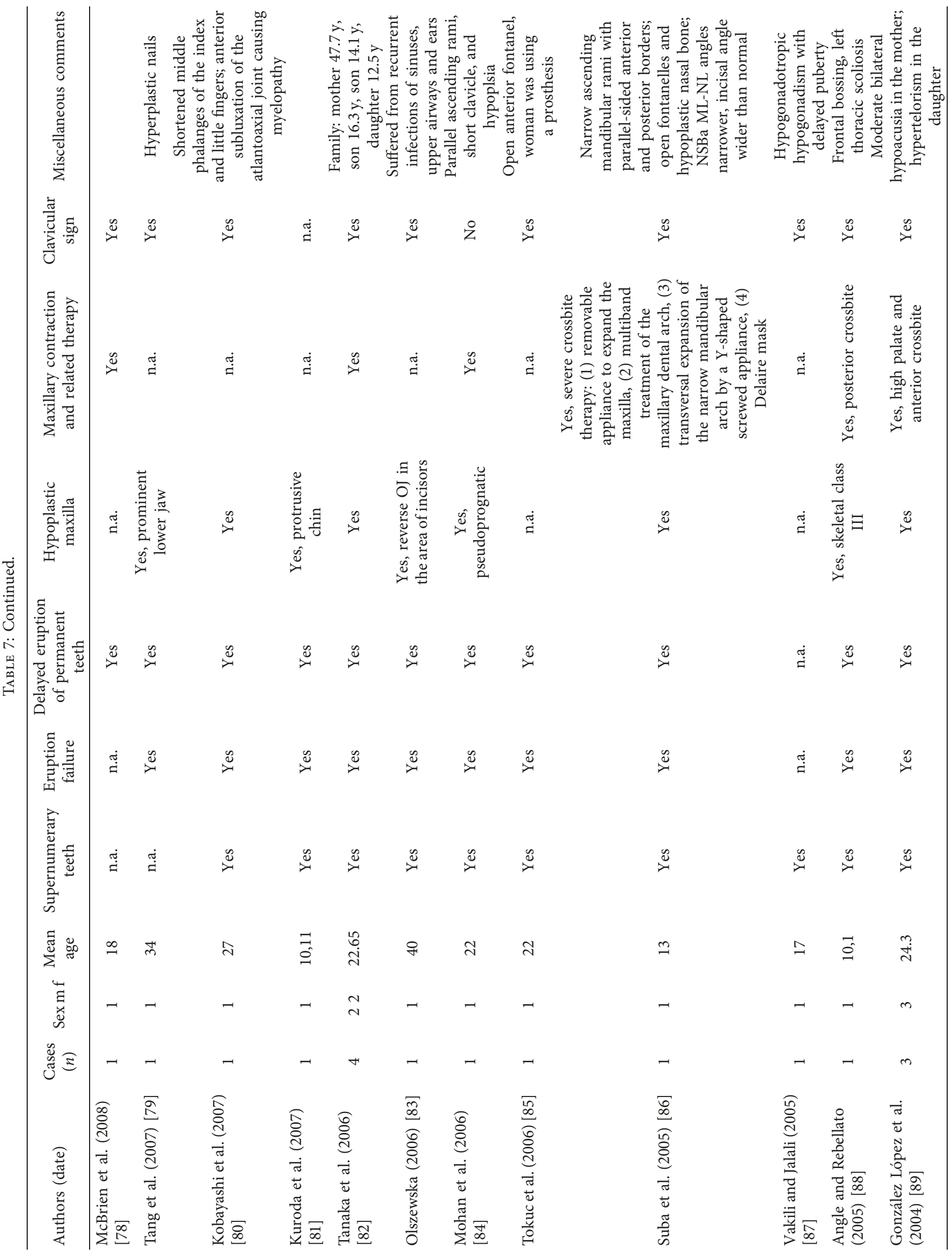




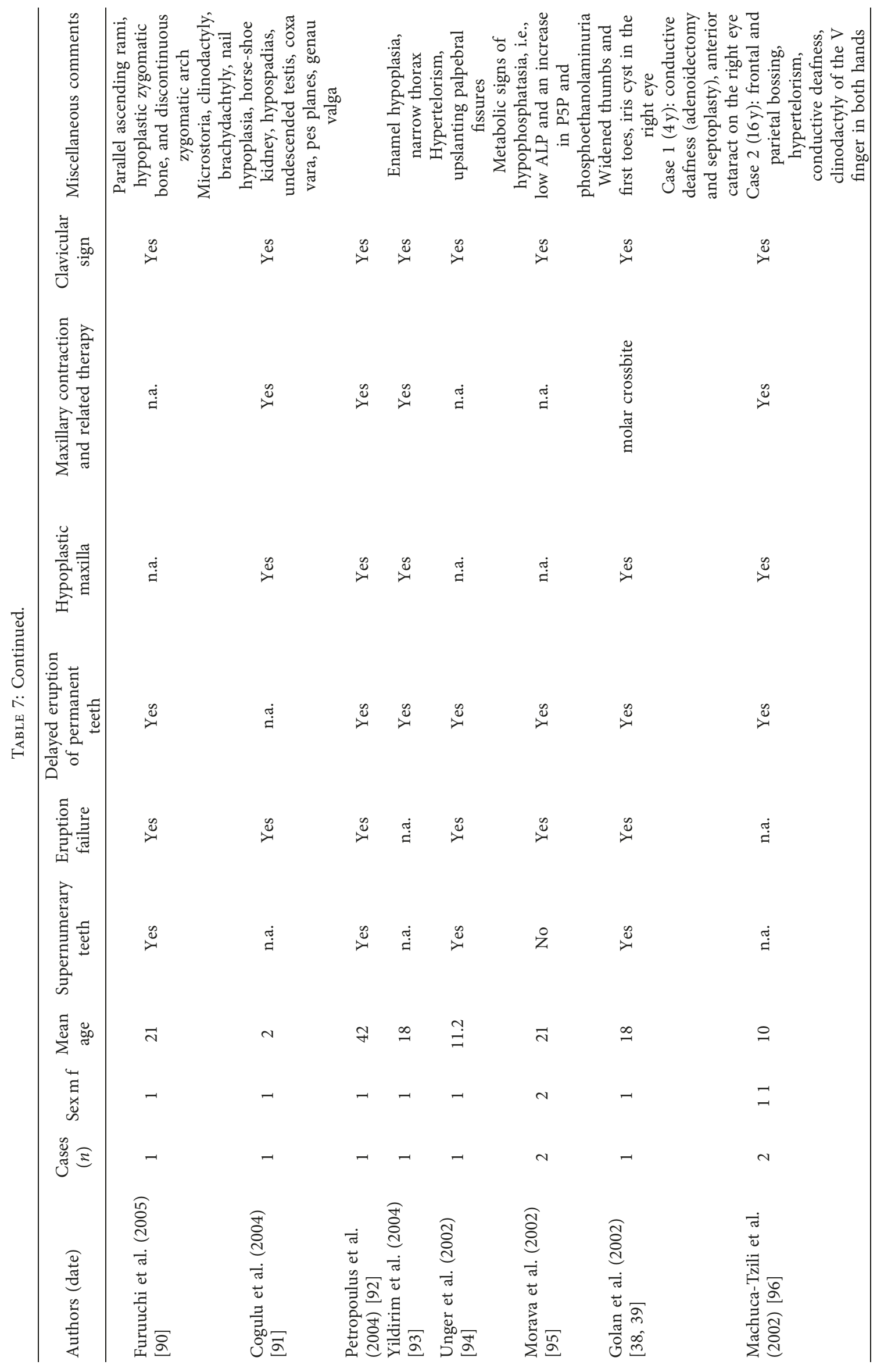




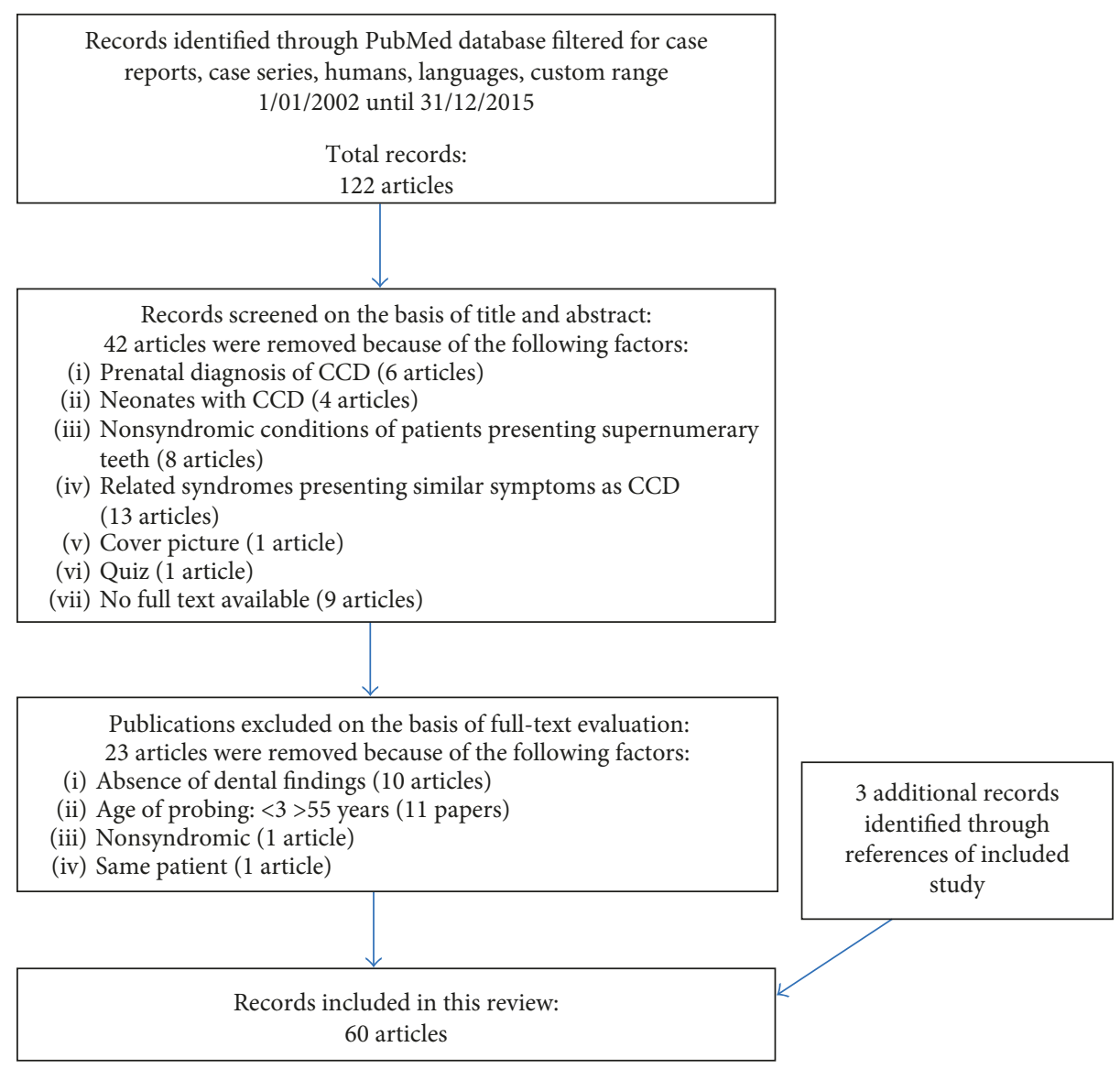

FIgURE 2: Results.

TABLE 8

\begin{tabular}{lcc}
\hline & Number of patients & $(\%)$ \\
\hline Total of patients & 79 & 100 \\
Females & 46 & 58.2 \\
Males & 33 & 41.8 \\
\hline
\end{tabular}

was treated with different orthodontic appliances: REP, Hyrax, transpalatal arch (TPA), and removable appliance (Schwartz appliance) followed by Delaire mask. All answered positively to orthodontic therapy (Table 9).

The second group consists of 33 males, mean age 18 years. All presented supernumerary teeth, eruption failure, delayed eruption of permanent teeth, maxillary contraction, and the clavicular sign. The maxillary contraction was treated in one case with crisscross elastics and in two cases with a TPA. Of these patients, $94 \%$ had hypoplastic maxilla; one case presented a class II jaw relationship, whereas all the others had a class III malocclusion. Two patients underwent orthognathic surgery for maxillary advancement and mandibular setback (Table 10).

4.1. Family Report. A family of three subjects, a mother and two siblings, has been analyzed in all the details of the clinical findings. A complete examination, both for the oral characteristics and for the general relevant data,
TABLE 9

\begin{tabular}{lcc}
\hline Clinical findings & Females & Males \\
\hline Mean age & 18.85 & 18 years \\
Supernumerary teeth & years & $100 \%$ \\
Eruption failure & $100 \%$ & $100 \%$ \\
Delayed eruption of permanent & $100 \%$ & $100 \%$ \\
teeth & $100 \%$ & $100 \%$ \\
Maxillary contraction & $100 \%$ & $100 \%$ \\
Clavicular sign & $100 \%$ & $94 \%$ \\
Hypoplastic maxilla & $98 \%$ & \\
& $2.5 \%$ & $0 \%$ \\
Missing of permanent teeth & $($ two & \\
& cases) & $1.2 \%$ (one \\
Class II malocclusion & & case) \\
Class III malocclusion & & $98.8 \%$ \\
\hline
\end{tabular}

TABLE 10

\begin{tabular}{lcc}
\hline Treatment options & & \\
& Females & Males \\
\hline REP & $100 \%$ & $100 \%$ \\
Hyrax & $100 \%$ & $100 \%$ \\
Transpalatal arch (TPA) & $100 \%$ & $100 \%$ \\
Removable appliance (Schwartz appliance) & $100 \%$ & $100 \%$ \\
Clavicular sign & $100 \%$ & $100 \%$ \\
\hline
\end{tabular}


TABLE 11: Case 1: orthodontic diagnosis summary.

\begin{tabular}{|c|c|c|}
\hline Facial and functional findings & Dental findings & Skeletal findings \\
\hline Brachyfacial & $\begin{array}{c}\text { Mixed dentition: All deciduous teeth except } 3.1 \\
\text { and } 1.6,2.6,3.6 \text { and } 4.6\end{array}$ & U-shaped upper and lower arches \\
\hline Concave profile & 5 supernumerary teeth in the upper jaw & Class I skeletal relationship \\
\hline Normotonic facial muscles & $\begin{array}{l}\text { Class I molar relation-ship, class I canine } \\
\text { deciduous relationship }\end{array}$ & $\begin{array}{c}\text { Reduced width of anterior cranial } \\
\text { base }\end{array}$ \\
\hline Mouth breathing & $\begin{array}{c}\text { Median lines are not coincident, the inferior is } \\
\text { deviated on the right }\end{array}$ & Reduced total divergency \\
\hline Atypical swallowing & Overjet reduced & Anterior rotation of maxilla \\
\hline $\begin{array}{l}\text { Normal insertion of labial and lingual } \\
\text { frenulum }\end{array}$ & Overbite reduced & $\begin{array}{c}\text { Counterclockwise rotational growth } \\
\text { Endoinclined lower incisors }\end{array}$ \\
\hline
\end{tabular}

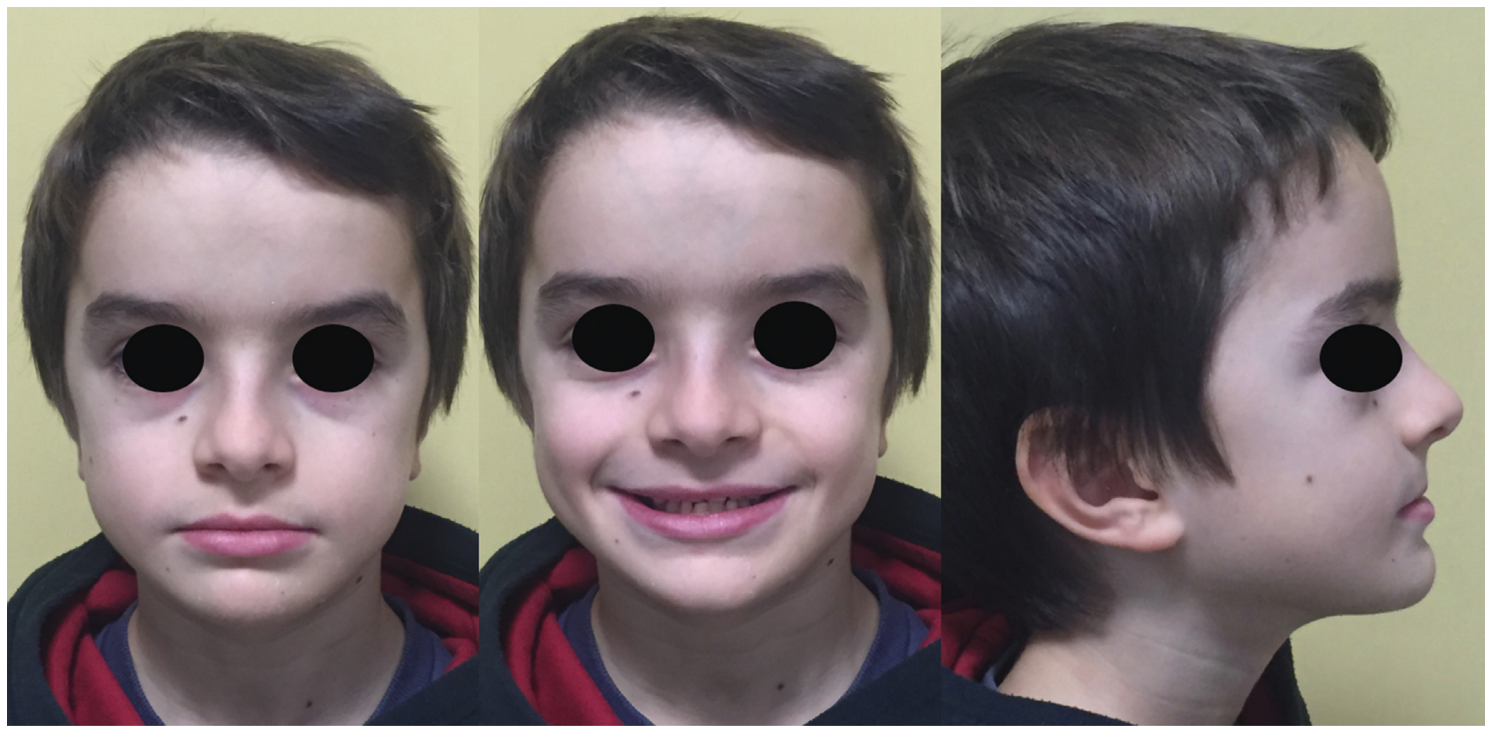

Figure 3: Case 1: pretreatment facial photographs.

is reported. For each case, a possible treatment plane has been hypothesized following the three therapeutic approachs illustrated above.

4.1.1. Case 1. A 12-year-old boy, S. R., came to an evaluation in October 2015 in the Orthodontic Department of Sapienza University of Rome. His weight was $24 \mathrm{~kg}(<3$ centile) and height was $1.20 \mathrm{~m}$ ( $<3$ centile), born from cesarean delivery at 39 weeks to a mother affected by CCD. He presented open fontanels and patent sutures at birth. Closure of anterior fontanel occurred at 3 years of age. In 2016, he underwent a complete clinical and auxological evaluation at the Department of Rare diseases of Sapienza University of Rome. His weight was $21.5 \mathrm{~kg}$ (25 centile) and height was $118.5 \mathrm{~cm}$ (25 centile), and the hand-wrist X-ray showed skeletal age of 6 years. Clinical examination showed narrow clavicles and accentuated joint mobility. The patient can oppose the shoulders on the midline. Orthopedic assessment showed left lumbar scoliosis and right dorsal scoliosis.

Audiological examination: normal audiometry and impedentiometry with tympanogram type A on the right and type $\mathrm{C}$ on the left. The cocleostapedial reflex was present bilaterally for both ipsilateral and contralateral stimulations.
(1) Laboratory findings: deficit of vitamin $\mathrm{D} 25-\mathrm{OH}$ $(17.5 \mathrm{ng} / \mathrm{ml})$, Beta-Cross Laps levels of $0.81 \mathrm{ng} / \mathrm{ml}$. DEXA $z$-score -2.8 .

$\mathrm{X}$-Ray of the spine (2 projections) and long bones (2 projections) shows pseudarthrosis of the medial third of both clavicles, that appears hypoplastic. Iliac wings appear squared and narrow. Hypoplastic pubic bones. Valgus femoral necks. Widened cephalic nuclei of the femoral bone. Proximal pseudoepiphysis of the second and fifth metacarpi in both hands. Brachy-telefalangy with hypoplastic nails. Retarded skeletal age between 6 and 7 years. TC of the head: mastoid appear thickened and ivory. Narrow antral cavities with thickened walls. Tympanic cavities with thickened walls. Cochlea surrounded by compact dense bone. Hyperemia of presphenoidal adenolymphoid tissues. Deviation of nasal septum.

The orthodontic diagnosis is summarized in Table 11 (Figures 3-8).

4.1.2. Treatment Planning. We will proceed using a twostage approach, like a "Jerusalem approach" to provide:

(i) Aesthetic for the patient in the frontal area because the time for eruption of the incisors is passed since 


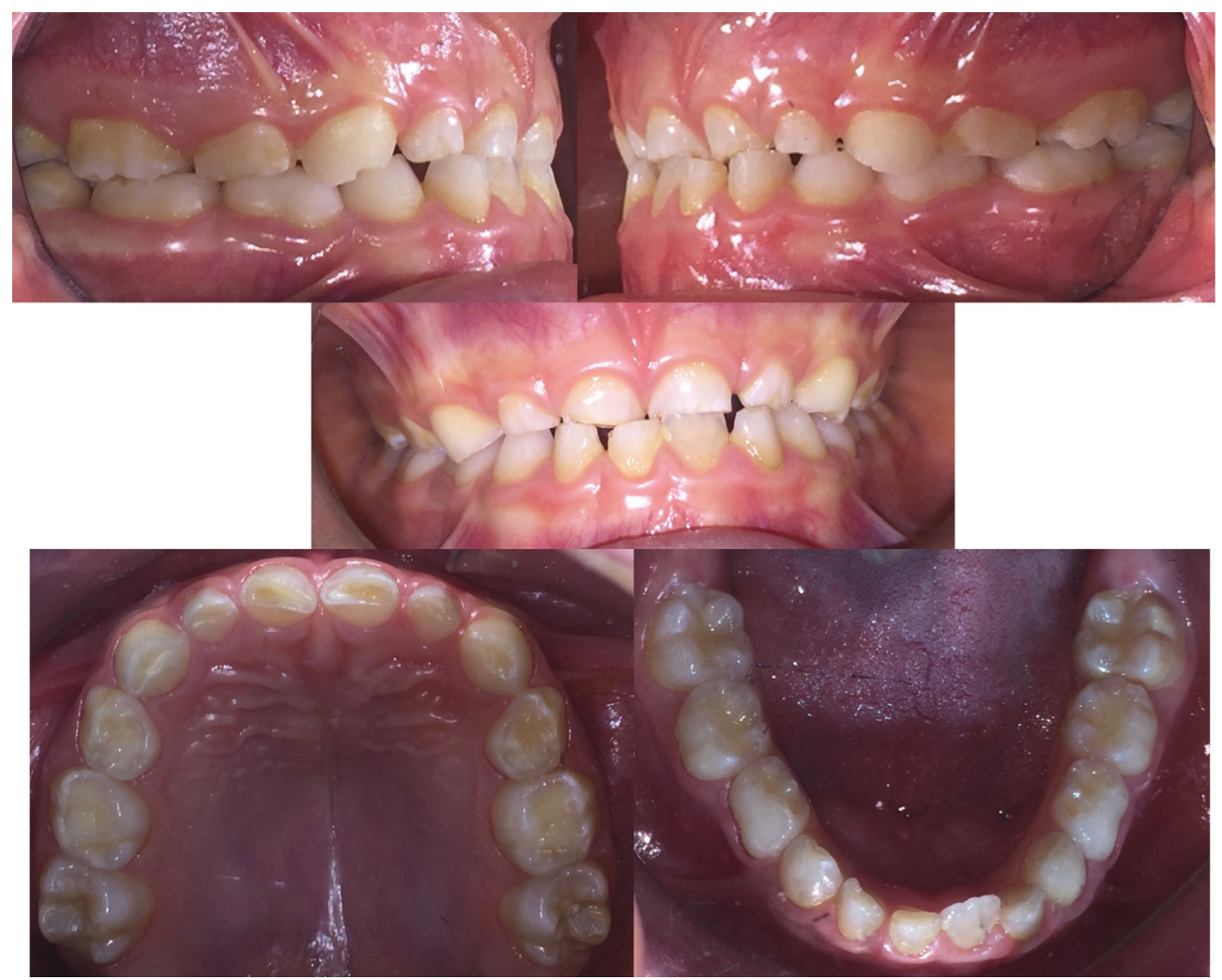

Figure 4: Case 1: intraoral photographs.



Figure 5: Study casts.

several years (although the patients shows delayed eruption of teeth and growth), it's important to exploit the residual vis a tergo of these teeth because the canines have the longest and most tortuous path of eruption, and they are located much higher than the crowns of the incisors. To provide this orthodontic approach firstly, the patient will require a skeletal expansion of the upper jaw. A Rapid palatal expander will be designed with bands on 1.6 and 2.6, rests on 5.4 and 6.4, with several arms and loops for the 


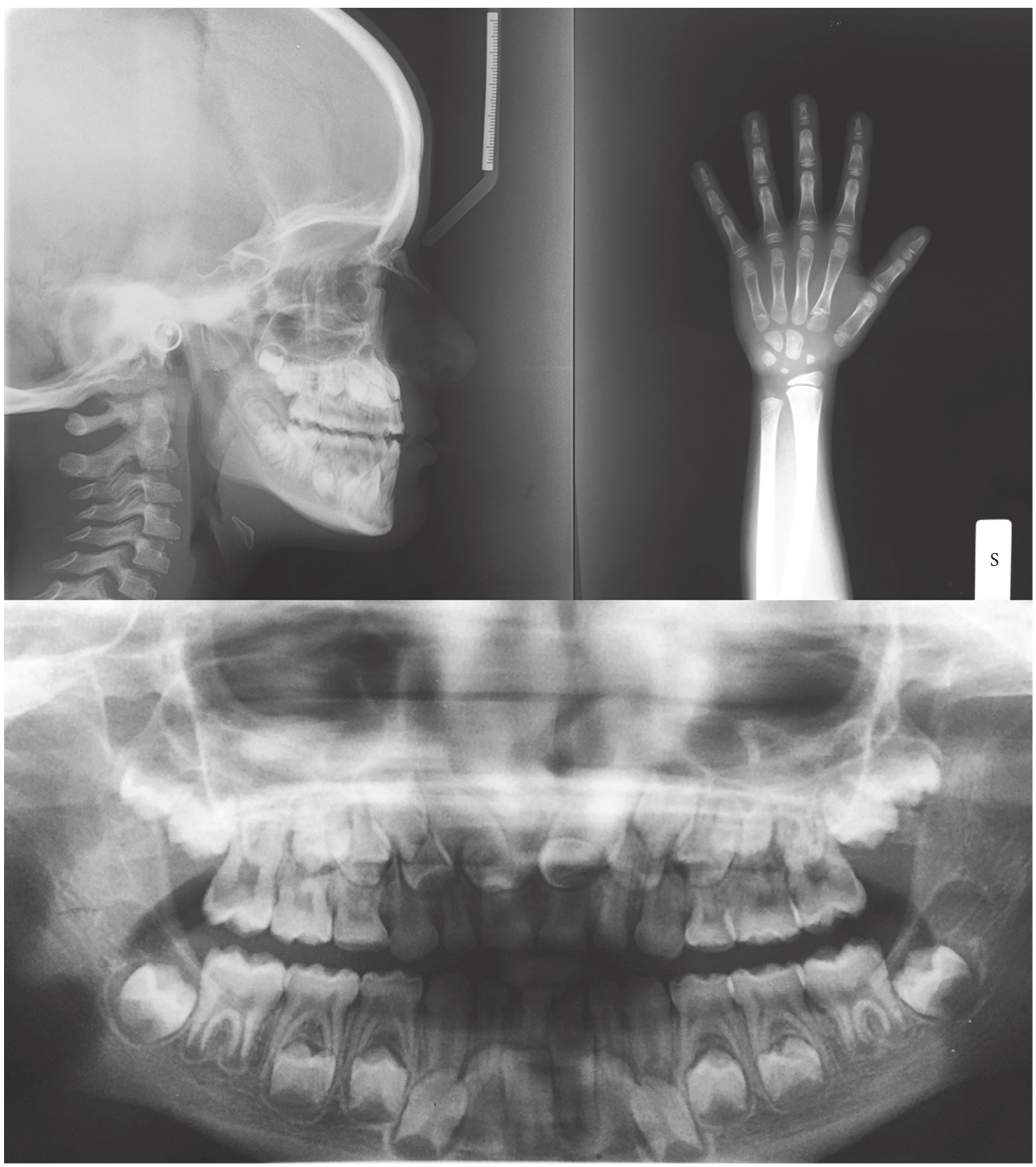

FIgURE 6: Radiographs of skull and panorex.

orthodontic traction of the central and lateral upper incisors.

After extraction of deciduous and supernumerary teeth of the anterior upper area, under general anesthesia, the 4 upper permanent incisors will be exposed and immediately bonded for traction under a closed flap. On the lower jaw, he will also need extraction of deciduous teeth. A lingual arch with rests on deciduous first molars and loops for the orthodontic traction of the lower incisors will be employed.

(ii) Only after disinclusion of all incisors, and after surgical removal of deciduous and supernumerary teeth, we will proceed with the lateral sectors, probably using an intraoral double arch, like the arch used with the Delaire mask, but provided of arms for the traction of canines.

4.1.3. Case 2. The patient S.A., older sister of the first patient, came to the orthodontic Department of the University "Sapienza" of Roma in October 2015 at the age of 17, with weight $62 \mathrm{~kg}$ and height $1.57 \mathrm{~m}$. Born from caesarian delivery at 37 weeks from mother affected by CCD. She underwent cataract surgery at two years. At the age of 3 years she underwent genetic counseling. X-Ray of the thorax showed missing ossification of median third of right clavicle; normal left clavicle. X-Ray of the skull evidenced Wormian bones. At 5 years of age she underwent adenotonsillectomy. 


\begin{tabular}{lcc}
\hline \multicolumn{3}{c}{ Sagittal skeletal values } \\
\hline SNA & $80^{\circ} \pm 2^{\circ}$ & $85^{\circ}$ \\
SNB & $78^{\circ} \pm 2^{\circ}$ & $83^{\circ}$ \\
ANB & $2^{\circ}-4^{\circ}$ & $2^{\circ}$ \\
NSBa & $130^{\circ}$ & $121^{\circ}$ \\
AOBO & $2 \mathrm{~mm}$ & $-3.5 \mathrm{~mm}$ \\
S-N mm & & $74 \mathrm{~mm}$ \\
Go-Me mm & & $68 \mathrm{~mm}$ \\
\hline \multicolumn{3}{c}{ Vertical skeletal values } \\
\hline FMA & $25^{\circ} \pm 3^{\circ}$ & $19^{\circ}$ \\
ML-NSL & $32^{\circ}$ & $26^{\circ}$ \\
NL-NSL & $8.5^{\circ}$ & $5^{\circ}$ \\
ML-NL & $23.5^{\circ}$ & $21^{\circ}$ \\
NSAr & $123^{\circ} \pm 5^{\circ}$ & $117^{\circ}$ \\
SArGo & $143^{\circ} \pm 6^{\circ}$ & $145^{\circ}$ \\
& $130^{\circ} \pm 7^{\circ}$ & $126^{\circ}$ \\
(i) NGoAr & $52^{\circ}-55^{\circ}$ & $54^{\circ}$ \\
(ii) NGoMe & $70^{\circ}-75^{\circ}$ & $72^{\circ}$ \\
& $396^{\circ} \pm 6^{\circ}$ & $388^{\circ}$ \\
\hline
\end{tabular}

\begin{tabular}{lcc}
\hline \multicolumn{3}{c}{ Dentoskeletal values } \\
\hline IMPA & $90^{\circ}$ & $77^{\circ}$ \\
FMIA & $65^{\circ}$ & $87^{\circ}$ \\
1 sup-NA & $4 \mathrm{~mm}$ & n.v. \\
1 inf-NB & $4 \mathrm{~mm}$ & $3 \mathrm{~mm}$ \\
1 sup-NA & $22^{\circ}$ & n.v. \\
1 inf-NB & $25^{\circ}$ & $7^{\circ}$ \\
1 sup-NL & $110^{\circ}$ & n.v. \\
1 sup-SNL & $103^{\circ}$ & n.v. \\
\hline \multicolumn{3}{c}{ Dental values } \\
\hline $1-1$ & $131^{\circ}$ & n.v.
\end{tabular}

Figure 7: Cephalometric analysis.

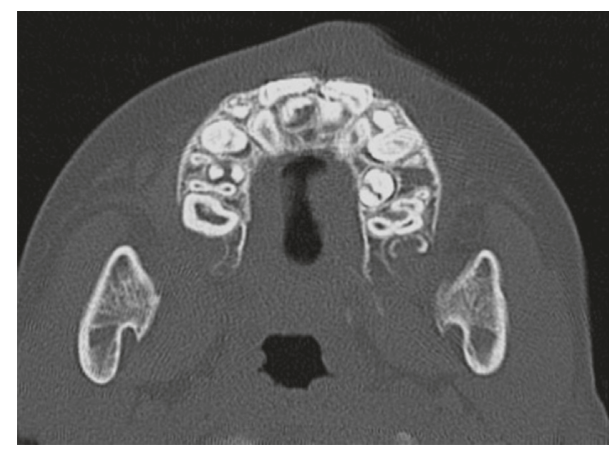

Figure 8: TC dentascan of upper arch.

Hypertrophy of turbinates remains. In 2014 another clinical assessment shows overweight (65 kg), short stature $(1.52 \mathrm{~m})$, discrete joint laxity, pes planus, genu valgus.

Audiological examination: normal audiometry and impedentiometry with tympanogram type $\mathrm{A}$ on the right and type $\mathrm{C}$ on the left. The cocleostapedial reflex was present bilaterally for both ipsilateral and contralateral stimulations. No alteration was evident on the TC scan of the middle ear.

(1) Laboratory findings: deficit of vitamin D 25-OH (19 ng/ml).

Orthopedic examination in 2015 shows left lumbar scoliosis, dorsal kyphosis, and bilateral scapula humeral anteversion, greater on the right. Bilateral genu valgus recurved. Pes planus valgus, flexible not painful, are also present.

X-ray of the spine (2 projections) and long bones (2 projections) shows convex dorsal left scoliosis with modest accentuation of dorsal kyphosis. Pseudarthrosis of the medial third of right clavicle. Slight hypoplastic left clavicle. Cervicocephalic valgism of both femoral necks. Slight curving of median third of both tibial diaphysis of the tibiofemoral joints.

DEXA Z-score -2.8. Skeletal age of 15-16 years.

The orthodontic diagnosis is summarized in Table 12 (Figures 9-14).

4.1.4. Treatment Planning. In this case, a single surgical stage approach was chosen, similar to the "BelfastHamburg" approach. The treatment will be performed using a double intraoral arch welded on bands on 16 and 26, provided of multiloops on both palatal and vestibular arch and secured with two mini-screws.

"Temporary anchorage devices" (TADs) inserted on the comfort zone of the palate aimed to provide orthodontic traction of 12,11 , and 22 in first place and afterwards canines and bicuspids.

Moreover, we want to use a double intraoral arch for the lower jaw as well. This will be provided of power arms to secure it by means of TADs placed on the vestibular mandibular cortical. All the teeth to be disimpacted will be bonded as possible in the same surgical phase.

4.1.5. Case 3. The mother of the siblings, P.F. 44 years old, weight $86 \mathrm{~kg}$ and height $1.54 \mathrm{~m}$ is also affected by CCD. She was born in podalic position by vaginal delivery and weighted 
TABLE 12: Case 2: orthodontic diagnosis summary.

\begin{tabular}{|c|c|c|}
\hline Facial and functional findings & Dental findings & Skeletal findings \\
\hline Brachycephalic & $\begin{array}{l}\text { Mixed dentition with presence of } 16,17,21 \text {, } \\
\qquad 26,27,31,36,37,41,46,47\end{array}$ & Contraction of upper jaw \\
\hline Concave profile with prognathic chin & $\begin{array}{c}6 \text { supernumerary teeth in the maxilla and } 5 \\
\text { in the lower jaw }\end{array}$ & Class III skeletal relationship \\
\hline $\begin{array}{l}\text { Normotonic facial muscles and masticatory } \\
\text { muscles }\end{array}$ & Class III molar relationship bilaterally & Reduced width of anterior cranial base \\
\hline Nasal breathing & $\begin{array}{l}\text { Class III deciduous canine relationship on } \\
\text { the left (lower canine is missing on the right) }\end{array}$ & Reduced divergence (SN/ML) $16^{\circ}$ \\
\hline \multirow{3}{*}{$\begin{array}{l}\text { Normal swallowing } \\
\text { Normal insertion of labial and lingual } \\
\text { frenulum }\end{array}$} & Centered dental midlines & Anterior rotation of maxilla \\
\hline & Overjet reduced & $\begin{array}{l}\text { Counterclockwise rotation of maxilla and } \\
\text { mandible }\end{array}$ \\
\hline & Overbite reduced & $\begin{array}{c}\text { Endoinclined lower incisors, proclined } \\
\text { upper incisors with normal interincisor } \\
\text { angle }\end{array}$ \\
\hline
\end{tabular}

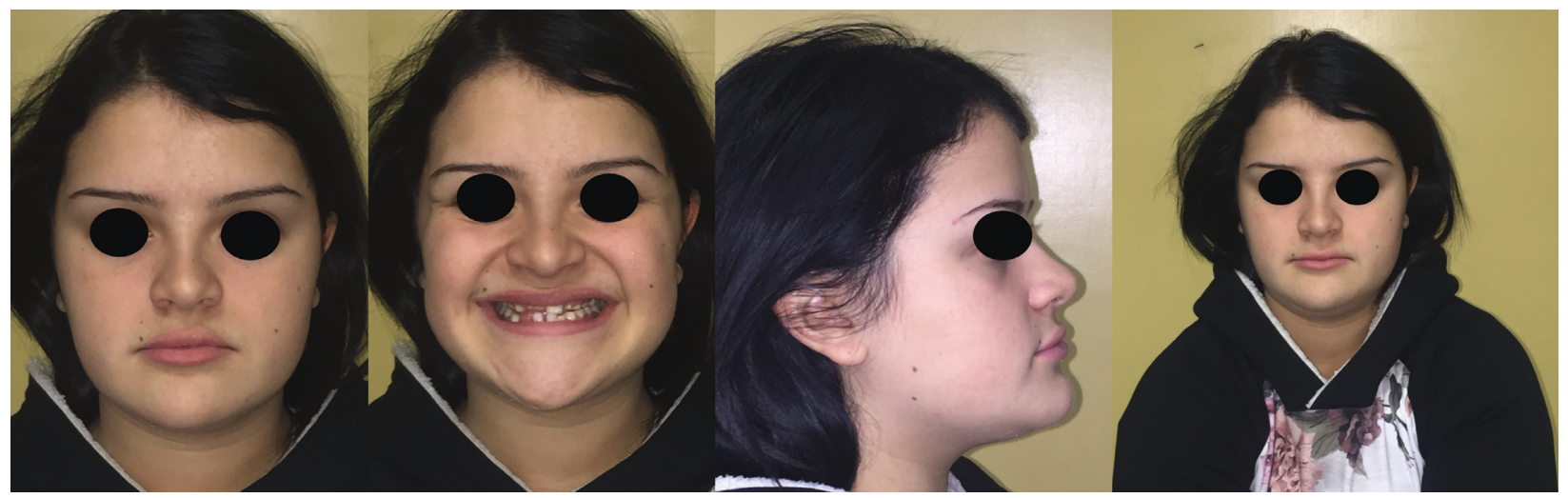

Figure 9: Case 1: pretreatment facial photographs.

$2.100 \mathrm{~g}$ at birth. She is allergic to Nichel and lanolin alcohol and presents a kidney with double calyx. She underwent surgery 4 times for kidney stones and one time for debridement of temporomandibular joint. When she was 15, she extracted supernumerary teeth and deciduous molars from the III quadrant of the mouth. Until the age of 30 years, she had only lost the four lower incisors and for the rest, was in deciduous dentition. In 2000, she began several surgeries for the extraction of deciduous teeth and supernumerary in the remaining quadrants. She reports to have until 3 supernumeraries for tooth. Finally, she underwent orthognathic surgery for advancement and expansion of the upper maxilla.

In 2014, she is sent by the Department of Maxillofacial Surgery to the Department of "Rare diseases" to assess a complete picture of the clinical and radiological situation before planning a mandibular setback for the resolution of the anterior crossbite. At the CT scan of the head, previously realized, important sclerosis of the cranial vault, with thickening of the interior and exterior planking, was visible: patent sutures and fontanels; important sclerosis of the cranial base, on the petrous part of the temporal bone; poor gasification of antral cavities and mastoids; deviated nasal septum; slight hypertelorism. X-ray of the spine (2 projections) and long bones (2 projections) shows hypoplastic clavicles with pseudoarthrosis of the median third: hypoplastic scapulae and glenoid fossae; small iliac wings; widened sacroiliac synchondrosis with sclerotic processes on the articular surfaces; thickened cortical of the femoral diaphysis; tibiofemoral valgism.

Laboratory findings show deficit of vitamin D $(25(\mathrm{OH})$ $\mathrm{D}, 18.1 \mathrm{ng} / \mathrm{mL})$, low levels of phosphates, and elevated level of PTH. The DXA showed a Z-score of -1.4 at the lumbar spine and -0.5 at the left hip. The pedigree of the family shows how the mutation did not skip any generation; this finding strongly points out an autosomal dominant inheritance pattern, characterized by the $50 \%$ risk of affected offspring. The mother of the grandfather and grandfather himself were affected by CCD (Figure 15). The patient is not sure yet if she wants to start a new treatment course and refused to realize the lateral Teleradiography because of the numerous previous unsuccessful interventions she underwent and the poor aesthetic results she obtained until today. For this reason, only the clinical, photographic, and plaster model findings were available.

The orthodontic diagnosis is summarized in Table 13 (Figure 16-18).

4.1.6. Treatment Planning. In this case, the hypnotized treatment planning would be realized with the "Bronx Approach." A complete engagement of the present teeth in an orthodontic fixed appliance will precede the surgical progressive exposition of the impacted and supernumerary 


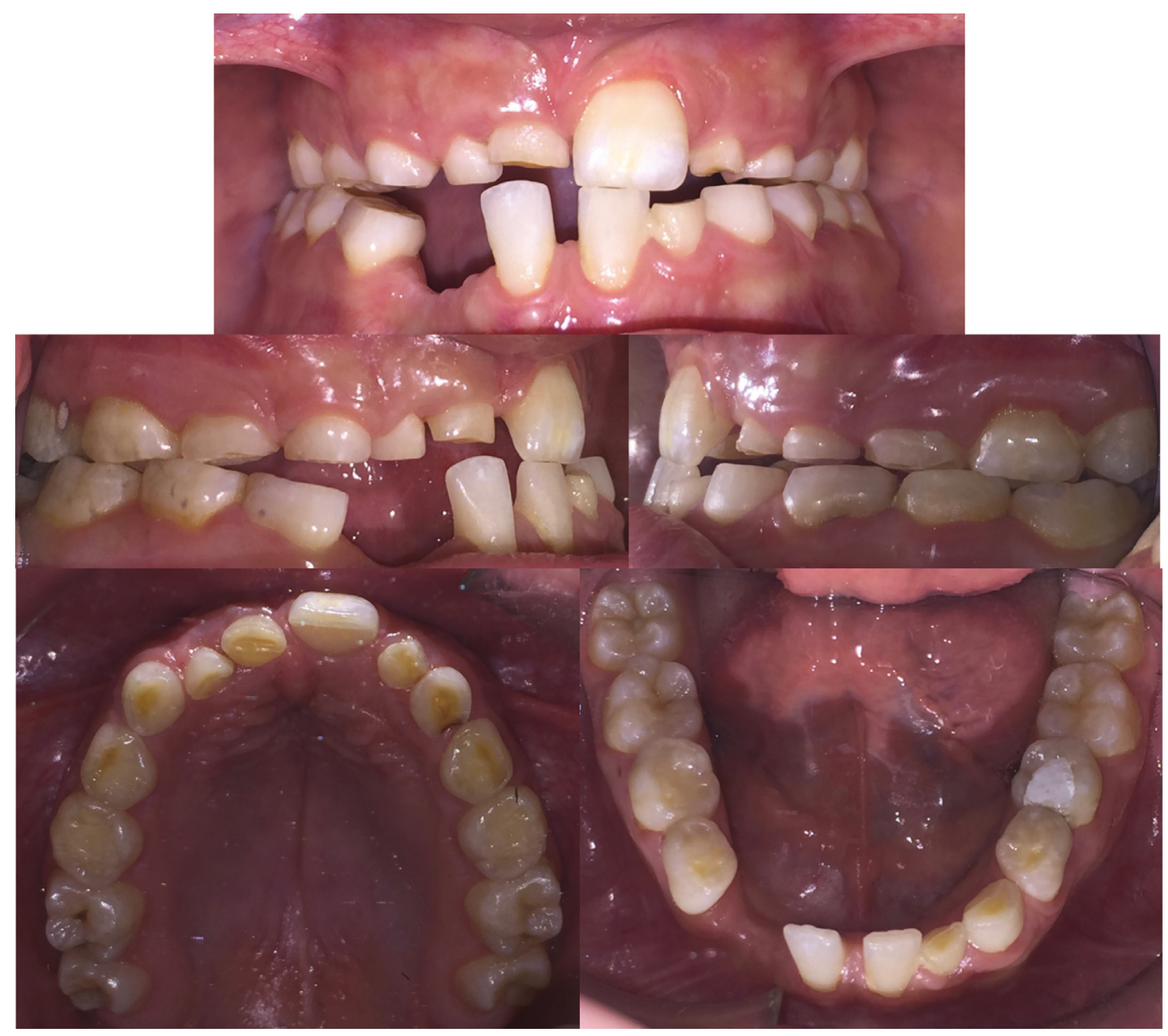

Figure 10: Case 1: intraoral photographs.

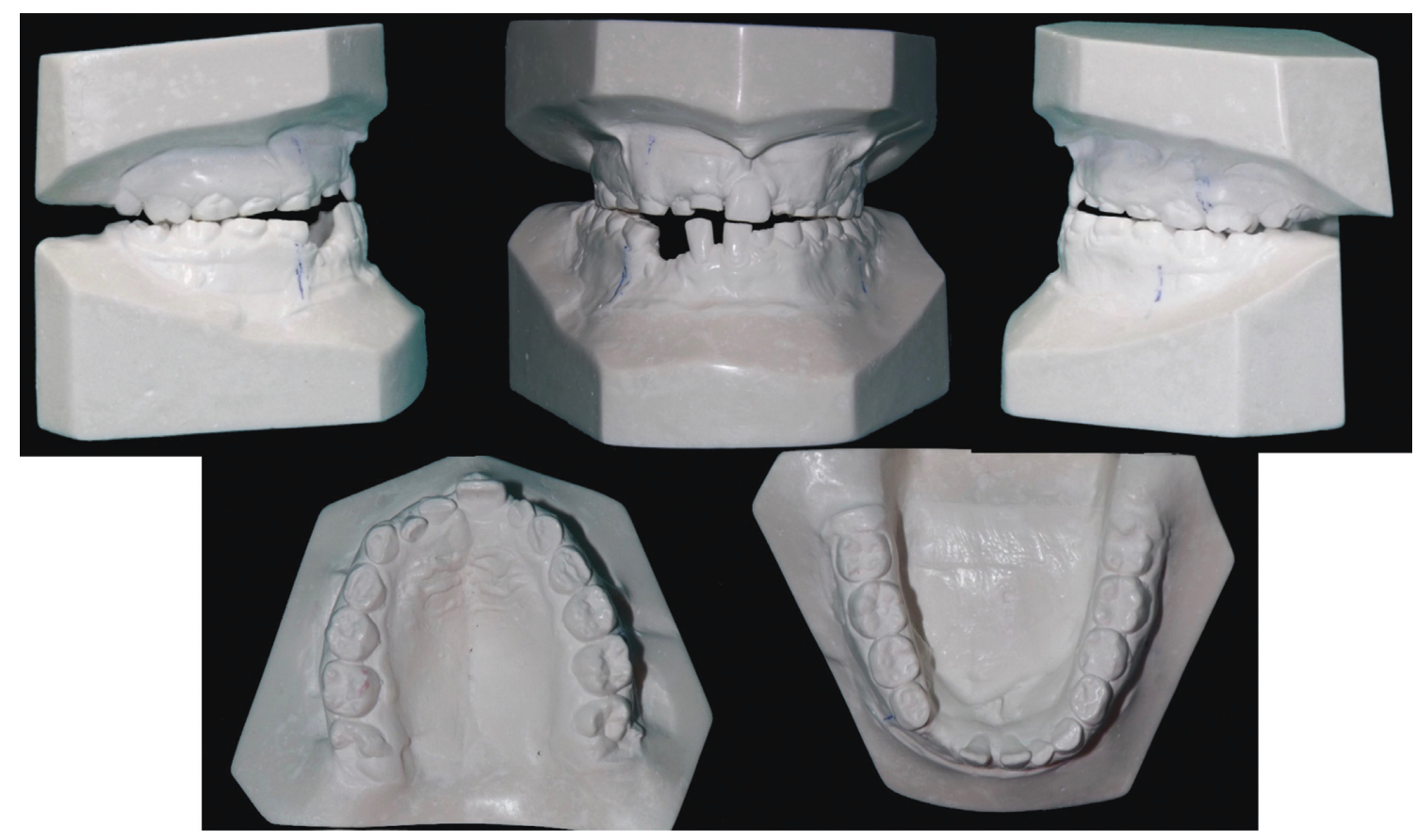

FIgURe 11: Study casts. 

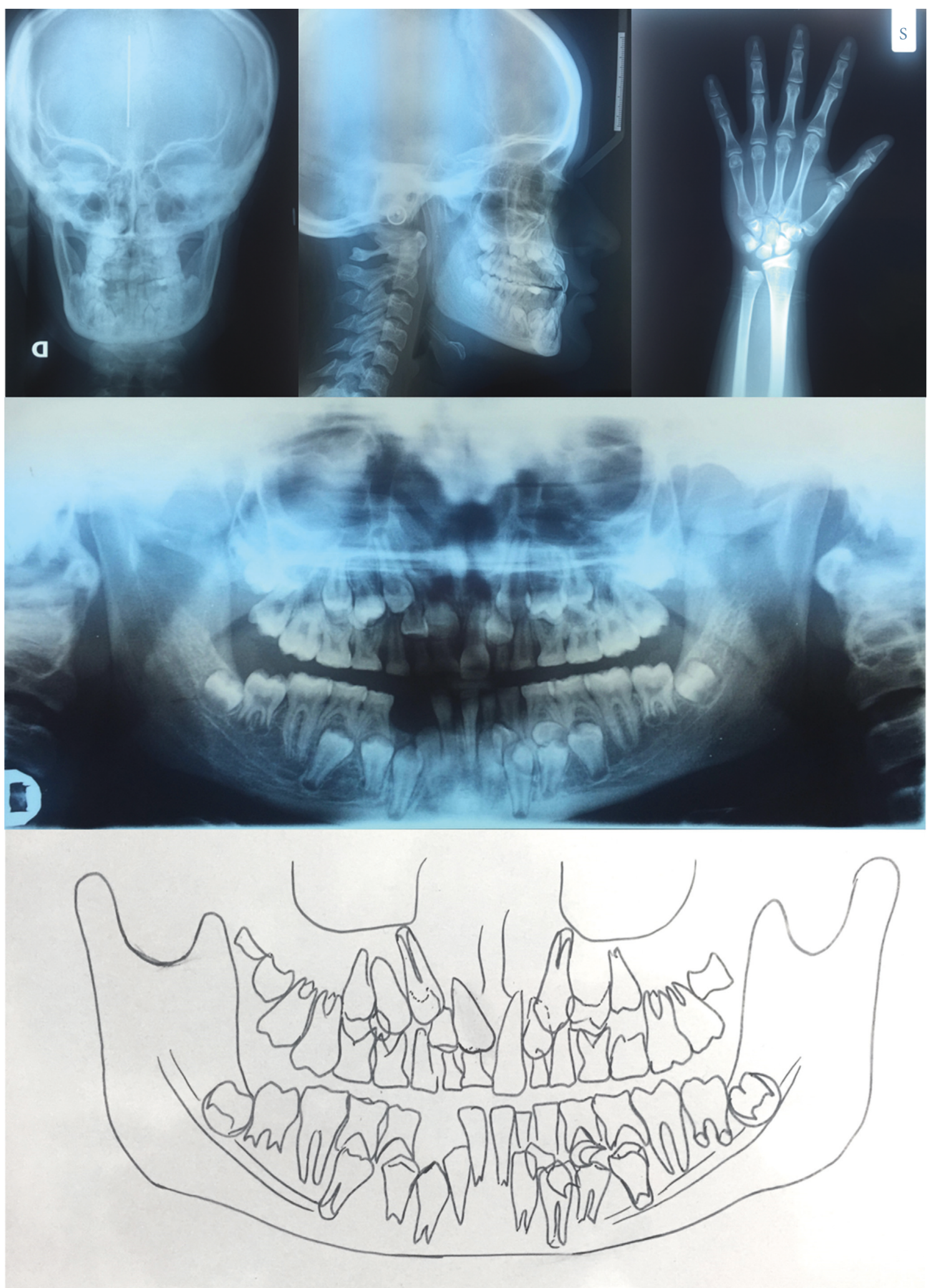

FIGURE 12: Radiographs of skull and panorex.

teeth. It is advisable to extract all the supernumerary teeth and of the impacted lower canines, due to their low horizontal position. The alignment and orthodontic traction of the impacted 1.3 will be realized, and the arches will be prepared for a subsequent orthognathic surgery of maxillary advancement and mandibular setback. The extraction of the impacted posterior molars will be realized in that occasion. A complete treatment of the gingivitis will 


\begin{tabular}{lcc}
\hline \multicolumn{3}{c}{ Sagittal skeletal values } \\
\hline SNA & $80^{\circ} \pm 2^{\circ}$ & $94^{\circ}$ \\
SNB & $78^{\circ} \pm 2^{\circ}$ & $95^{\circ}$ \\
ANB & $2^{\circ}-4^{\circ}$ & $-1^{\circ}$ \\
NSBa & $130^{\circ}$ & $119^{\circ}$ \\
AOBO & $2 \mathrm{~mm}$ & $-6 \mathrm{~mm}$ \\
S-N mm & & $67 \mathrm{~mm}$ \\
Go-Me mm & & $70 \mathrm{~mm}$ \\
\hline \multicolumn{3}{c}{ Vertical skeletal values } \\
\hline FMA & $25^{\circ} \pm 3^{\circ}$ & $12^{\circ}$ \\
ML-NSL & $32^{\circ}$ & $16^{\circ}$ \\
NL-NSL & $8.5^{\circ}$ & $4^{\circ}$ \\
ML-NL & $23.5^{\circ}$ & $12^{\circ}$ \\
NSAr & $123^{\circ} \pm 5^{\circ}$ & $114^{\circ}$ \\
SArGo & $143^{\circ} \pm 6^{\circ}$ & $143^{\circ}$ \\
ArGoMe & $130^{\circ} \pm 7^{\circ}$ & $121^{\circ}$ \\
(i) NGoAr & $52^{\circ}-55^{\circ}$ & $50^{\circ}$ \\
(ii) NGoMe & $70^{\circ}-75^{\circ}$ & $72^{\circ}$ \\
\hline & $396^{\circ} \pm 6^{\circ}$ & $378^{\circ}$ \\
\hline
\end{tabular}

\begin{tabular}{lcc}
\hline \multicolumn{3}{c}{ Dentoskeletal values } \\
\hline IMPA & $90^{\circ}$ & $78^{\circ}$ \\
FMIA & $65^{\circ}$ & $90^{\circ}$ \\
1 sup-NA & $4 \mathrm{~mm}$ & $4 \mathrm{~mm}$ \\
1 inf-NB & $4 \mathrm{~mm}$ & $3 \mathrm{~mm}$ \\
1 sup-NA & $22^{\circ}$ & $20^{\circ}$ \\
1 inf-NB & $25^{\circ}$ & $11^{\circ}$ \\
1 sup-NL & $110^{\circ}$ & $120^{\circ}$ \\
1 sup-SNL & $103^{\circ}$ & $116^{\circ}$ \\
\hline \multicolumn{3}{c}{ Dental values } \\
\hline $1-1$ & $131^{\circ}$ & $130^{\circ}$ \\
\hline
\end{tabular}

FIGURE 13: Cephalometric analysis.

precede all the orthodontic and surgical phases. A restorative reconstruction of the damaged elements will follow the complete orthodontic and surgical procedures.

\section{Discussion}

This report reviews 79 patients with CCD excluding all children under the age of 2 years and over 60 . The presence of dental signs such as supernumerary teeth, delayed eruption of permanent teeth, and eruption failure are almost constant in all patients. The family we observed at our Orthodontic Department shows all these dental findings. Such high percentage of dental problems underlines the importance of early diagnosis and multidisciplinary treatment for more reasons.

(1) The surgical and orthodontic techniques involved in the dental management of this condition are demanding at the levels of diagnosis, treatment planning, and clinical management. Thus, to achieve the best possible result, the highest degrees of orthodontic and surgical cooperation are necessary.

(2) Starting the treatment early with so many surgical procedures can be challenging for a young child but offers the advantage that the patient will have restored function and esthetics in adolescence, which can be psychologically important [9].

(3) The natural eruption of teeth with roots should be allowed after the removal of obstacles, such as deciduous or supernumerary teeth.
(4) The lack of eruption in patients with CCD is due to failure of resorption of the overlying alveolar bone. When these teeth are uncovered, they show a normal eruption pattern. There can also be mechanical interference from impacted supernumerary teeth.

(5) Moreover, sagittal deficiency of the upper jaw was investigated. This characteristic of the skull was found in almost all patients reported.

Some peculiarities are seen in the cephalometric measurements of a patient with CCD. Because the base of the skull is smaller than in patients who do not have the syndrome, measurements such as SNA, SNB, and facial angles appear greatly increased compared with normal ones. In addition, CCD is usually seen in a brachycephalic patient with horizontal growth, expressed by diminished measurements such as the $y$-axis, FMA, and SN/GoGn [9].

The familiar group with cleidocranial dysplasia, studied in the second part of our study, shows most of the characteristics found in the literature.

At the cephalometric examination of our patients, both showed reduced width of the anterior cranial base. The sister has a skeletal class III jaw relationship, according to both ANB and $\mathrm{AOBO}$, which we aim at correcting with Le Fort I advancement of the maxilla at the end of presurgical orthodontic treatment. The mother already underwent a maxillary surgical-assisted expansion, but still requires presurgical orthodontic treatment, extraction of supernumerary teeth, and 




Figure 14: TC dentascan of both arches.
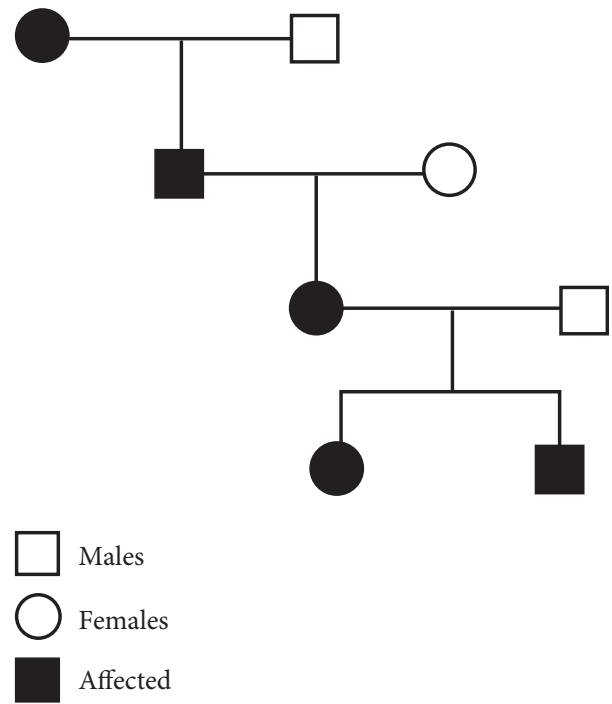

Figure 15: Pedigree of the family affected by CCD.

BSSO surgery for mandibular setback and correction of the anterior crossbite.

The younger son is now in Class I relationship and presents a marked failure to thrive. The mandibular bone growth continues in boys even after completion of statural according to the growth curves of Björk [97].

Sagittal jaw relationship will be monitored during the following years, but the correction of the transversal 
TABLE 13: Case 3: orthodontic diagnosis summary.

\begin{tabular}{|c|c|}
\hline Facial and functional findings & Dental findings \\
\hline Brachycephalic, symmetric & $\begin{array}{c}\text { Presence of } 1.1,1.2,(1.3 \text { impacted) supernumerary, } 1.4,1.6,1.7,(1.8 \\
\text { impacted) } 2.1,2.2,2.3,2.4,2.5,2.6,2.7,2.8,(2.9 \text { impacted) } 3.1,3.2,7.3(3.3 \\
\text { impacted) } 3.4,3.5, \text { (supernumerary impacted) } 3.6 \text {, (3.8 impacted), } 4.1,4.2,4.3 \\
(2 \text { impacted supernumerary) } 4.4,4.5,4.6 \text {, (impacted } 4.8) \text {. }\end{array}$ \\
\hline Concave profile with prognathic chin & 6 supernumerary teeth in the maxilla and 5 in the lower jaw \\
\hline Reverse smile arch, with lower incisors exposure & Class III molar relationship bilaterally \\
\hline Not visible keratinized gengiva & Class III canine relationship nonapplicable \\
\hline Normotonic facial muscles and masticatory muscles & Not centered dental midlines \\
\hline Nasal breathing & Overjet: $-0.5 \mathrm{~mm}$; overbite: $0 \mathrm{~mm}$ \\
\hline \multirow[t]{6}{*}{ Normal swallowing } & Accentuated Spee curve \\
\hline & Crossbite between 16 and 46 \\
\hline & Dental midlines noncoincident (upper deviated on the left) \\
\hline & Poor oral hygiene \\
\hline & Endodontic treatment on 3.6 and 4.6 \\
\hline & Mobility of $1.6,2.6,3.6,4.6$ \\
\hline
\end{tabular}

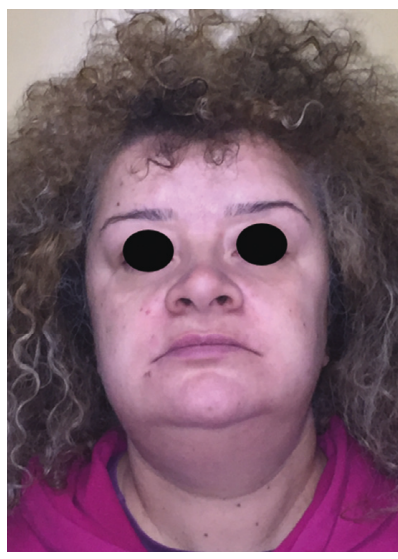

(a)

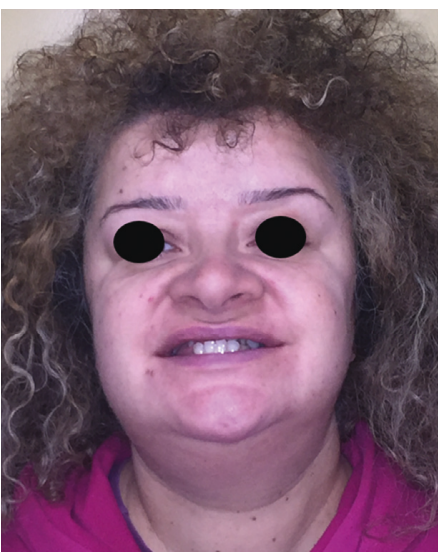

(b)

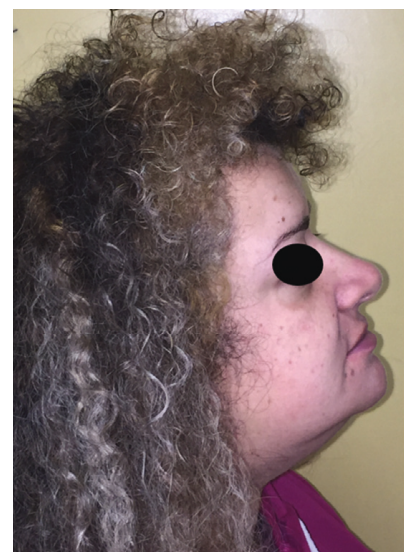

(c)



(d)

Figure 16: Case 3: extraoral pictures.

discrepancy and forced orthodontic eruption of upper and lower incisors are the main concern at this time point.

The reports of literature described various appliances (REP, TPA, and HYRAX) for the transversal correction, and none reported a failure of such procedure.

Finally, it is important to underline the importance of bone anchorage for the orthodontic traction of the impacted teeth. Skeletal anchorage in orthodontics as absolute anchorage provides new opportunity to guide impacted teeth into occlusion and to treat patients with CCD, making it possible to induce eruption simultaneously of the maxillary and mandibular teeth and consequently reducing patients' treatment times and psychological stress [98].

This is our aim in the treatment of the older sister: secure two double-arch wires by fixing them to the median or paramedian anterior palate using two mini-screws in the upper jaw and to the inter-radicular septum of the dentulous alveolar process in the mandible. This will provide maximum anchorage for the forced eruption of impacted teeth, without affecting the only permanent teeth present now (upper and lower first and second molars).

\section{Conclusion}

Revision of the literature is vital for the treatment planning of difficult cases, such as individuals affected by rare diseases, which involve numerous aspects of oral health; CCD is challenging for both the dental team and the patient. The treatment requires a multidisciplinary approach and a strong compliance through many years. A treatment of such condition can last years. It is very important to constantly motivate the patient to full compliance and to keep a scrupulous oral hygiene to avoid the risks that come with orthodontic treatment.

Further studies are required to better understand the cause of delayed eruption of permanent teeth and the abnormal presence of numerous supernumerary teeth that interfere with normal shading of primary dentition.

With the advancement of orthodontic techniques, together with the use of cone-beam for better understanding of the patients' dental situation and the TADs for skeletal anchorage, the treatment results will be greater in future. 


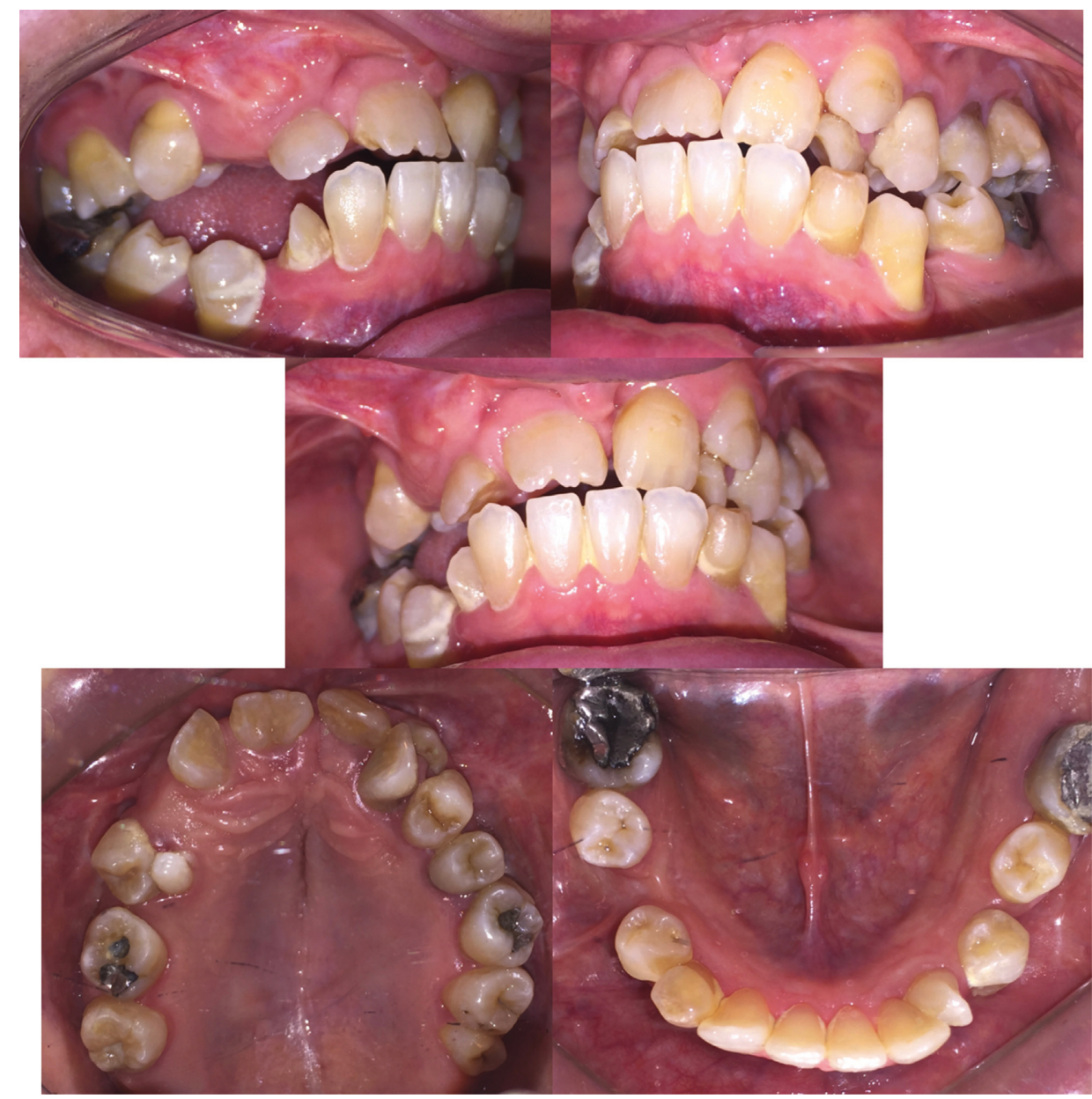

Figure 17: Case 3: intraoral findings.

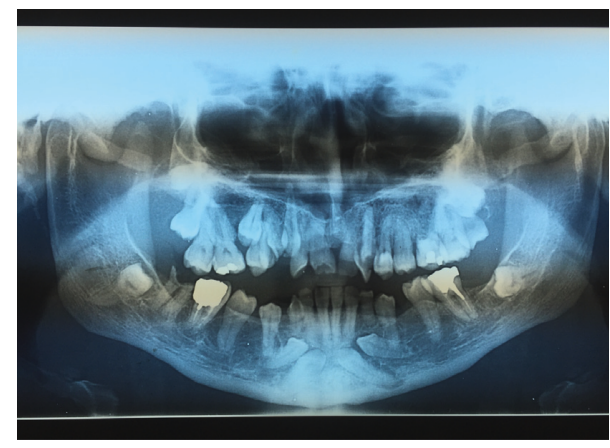

Figure 18: Case 3: radiological findings: OPT.

According to this review, we chose to treat our patients following a multistep approach thus enhancing the possibilities to achieve the recovery of the most possible number of teeth, to obtain a good occlusion and a better aesthetic, especially of the anterior region. The treatment of the adult patient is obviously requiring a multidisciplinary approach due to the need of surgical correction of the sagittal and transversal discrepancies and due to the need of a prosthetic reconstruction of the missing teeth. A strong suggestion of an early diagnosis and an early treatment seem then to be mandatory to improve the prognosis of the cleidocranialrelated anomalies.

\section{Conflicts of Interest}

The authors declare that they have no conflicts of interest.

\section{References}

[1] R. Mendoza-Londono and B. Lee, Cleidocranial Dysplasia GeneReviews $^{\circledR}$, Seattle (WA), University of Washington, Seattle, WA, USA, 2006.

[2] F. Otto, H. Kanegane, and S. Mundlos, "Mutations in the RUNX2 gene in patients with cleidocranial dysplasia," $\mathrm{Hu}$ man Mutation, vol. 19, no. 3, pp. 209-216, 2002.

[3] M. G. Arvystas, "Familial generalized delayed eruption of the dentition with short stature," Oral Surgery, Oral Medicine, Oral Pathology, vol. 41, no. 2, pp. 235-243, 1976.

[4] D. D. Dore, G. D. MacEwen, and M. I. Boulos, "Cleidocranial dysostosis and syringomyelia: review of the literature and case report," Clinical Orthopaedics and Related Research, vol. 214, pp. 229-234, 1987.

[5] B. L. Jensen, "Somatic development in cleidocranial dysplasia," American Journal of Medical Genetics, vol. 35, no. 1, pp. 69-74, 1990. 
[6] D. Chitayat, K. A. Hodgkinson, and E. M. Azouz, "Intrafamilial variability in cleidocranial dysplasia: a three generation family," American Journal of Medical Genetics, vol. 42, no. 3, pp. 298-303, 1992.

[7] R. S. Ramesar, J. Greenberg, R. Martin et al., "Mapping of the gene for cleidocranial dysplasia in the historical Cape Town (Arnold) kindred and evidence for locus homogeneity," Journal of Medical Genetics, vol. 33, no. 6, pp. 511-514, 1996.

[8] W. P. U. Jackson, "Osteo-dental dysplasia (cleido-cranial dysostosis). The "Arnold head"," Acta Medica Scandinavica, vol. 139, no. 4, pp. 292-307, 1951.

[9] T. Roberts, L. Stephen, and P. Beighton, "Cleidocranial dysplasia: a review of the dental, historical, and practical implications with an overview of the South African experience," Oral Surgery, Oral Medicine, Oral Pathology and Oral Radiology, vol. 115, no. 1, pp. 46-55, 2013.

[10] S. Mundlos, "Cleidocranial dysplasia: clinical and molecular genetics," Journal of Medical Genetics, vol. 36, no. 3, pp. 177-182, 1999.

[11] U. Romeo, G. Galluccio, G. Palaia et al., "Cleidocranial dysplasia: maxillary alterations on the transverse plane. Presence of crown-radicular anomalies and multidisciplinary approach of a clinical case," Oral Health and Dental Management, vol. 13, no. 2, pp. 529-535, 2014.

[12] S. C. Cooper, C. M. Flaitz, D. A. Johnston, B. Lee, and J. T. Hecht, "A natural history of cleidocranial dysplasia," American Journal of Medical Genetics, vol. 104, no. 1, pp. 1-6, 2001.

[13] H. Yamamota, T. Sakart, and J. E. Davies, "Cleidocranial dysplasia: a light microscope, electron microscope and crystallographic study," Oral Surgery, Oral Medicine, Oral Pathology, vol. 68, no. 2, pp. 195-200, 2008.

[14] T. K. N. Park, K. Vargervik, and S. Oberoi, "Orthodontic and surgical management of cleidocranial dysplasia," Korean Journal of Orthodontics, vol. 43, no. 5, pp. 248-260, 2013.

[15] R. W. Berg, K. S. Kurtz, I. Watanabe, and A. Lambrakos, "Interim prosthetic phase of multidisciplinary management of cleidocranial dysplasia: "the Bronx Approach"," Journal of Prosthodontics, vol. 20, pp. S20-S25, 2011.

[16] Y. W. Guo, C. Y. Chiu, C. L. Liu, T. S. Jap, and L. Y. Lin, "Novel mutation of RUNX2 gene in a patient with cleidocranial dysplasia," International Journal of Clinical and Experimental Pathology, vol. 8, no. 1, pp. 1057-1062, 2015.

[17] R. P. Anthonappa, F. Yan-Hui, N. M. King, A. B. Rabie, and S. You-Qiang, "Novel complex disease allele mutations in cleidocranial dysplasia patients," Journal of Oral Pathology and Medicine, vol. 43, no. 10, pp. 798-800, 2014.

[18] T. Takenouchi, W. Sato, C. Torii, and K. Kosaki, "Progressive cognitive decline in an adult patient with cleidocranial dysplasia," European Journal of Medical Genetics, vol. 57, no. 7, pp. 319-321, 2014.

[19] M. Rallan, N. S. Rallan, M. Goswami, and K. Rawat, "Surgical management of multiple supernumerary teeth and an impacted maxillary permanent central incisor," Case Reports, vol. 22, p. bcr2013009995, 2013.

[20] C. J. Wang and S. M. Neustein, "General anesthesia in a patient with cleidocranial dysplasia," Middle East Journal of Anesthesiology, vol. 21, no. 6, pp. 889-890, 2012.

[21] M. Matsushita, H. Kitoh, H. Kaneko et al., "A novel in-frame deletion of the RUNX2 gene causes a classic form of cleidocranial dysplasia," Journal of Bone and Mineral Metabolism, vol. 32, no. 1, pp. 96-99, 2014.
[22] I. Broeks, I. E. Veenstra-Knol, and A. W. Kamps, "A rare presentation of cleidocranial dysplasia," BMJ Case Reports, vol. 2012, p. bcr0320126101, 2012.

[23] A. Gardham, E. Forsythe, and N. Goulden, "One in 10 million: a case of cleidocranial dysplasia and acute lymphoblastic leukaemia-more than just a coincidence?," Clinical Dysmorphology, vol. 21, no. 3, pp. 170-171, 2012.

[24] J. K. Northup, R. Matalon, L. H. Lockhart, J. C. Hawkins, and G. V. Velagaleti, "A complex chromosome rearrangement, der (6)ins(6)(p21.1q25.3q27)inv(6)(p25.3q27), in a child with cleidocranial dysplasia," European Journal of Medical Genetics, vol. 54, no. 4, pp. e394-e398, 2011.

[25] B. M. Cardoso, J. Dupont, S. Castanhinha et al., "Cleidocranial dysplasia with severe parietal bone dysplasia: a new (p. Val124Serfs) RUNX2 mutation," Clinical Dysmorphology, vol. 19, no. 3, pp. 150-152, 2010.

[26] Z. Shen, C. C. Zou, R. W. Yang, and Z. Y. Zhao, "Cleidocranial dysplasia: report of 3 cases and literature review," Clinical Pediatrics, vol. 48, no. 2, pp. 194-198, 2009.

[27] K. Manjunath, B. Kavitha, T. R. Saraswathi, B. Sivapathasundharam, and R. Manikandhan, "Cementum analysis in cleidocranial dysostosis," Indian Journal of Dental Research, vol. 19, no. 3, pp. 253-256, 2008.

[28] O. N. Pamuk, S. Mundlos, and N. Cakir, "Cleidocranial dysplasia in a mother and her two children," Joint Bone Spine, vol. 75, no. 6, pp. 725-727, 2008.

[29] A. S. Issever, G. Diederichs, and J. Tuisher, "Diagnosis of cleidocranial dysplasia in routine chest radiograph," Circulation, vol. 116, no. 5, pp. e116-e118, 2007.

[30] T. Pal, D. Napierala, T. A. Becker et al., "The presence of germ line mosaicism in cleidocranial dysplasia," Clinical Genetics, vol. 71, no. 6, pp. 589-591, 2007.

[31] D. D. Fernandes, G. B. Marshall, and J. B. Frizzell, "Answer to case of the month \#111: Cleidocranial dysostosis," Canadian Association of Radiologists Journal, vol. 57, no. 4, pp. 246-248, 2006.

[32] M. L. Cunningham, M. L. Seto, A. V. Hing, M. J. Bull, R. J. Hopkin, and K. A. Leppig, "Cleidocranial dysplasia with severe parietal bone dysplasia: C-terminal RUNX2 mutations," Birth Defects Research Part A: Clinical and Molecular Teratology, vol. 76, no. 2, pp. 78-85, 2006.

[33] W. Campos Júnior, R. M. Cardoso, R. Fidelis, E. S. Silva, and R. Ramos, "A familial case of cleidocranial dysostosis presenting upper limb ischemia," Sao Paulo Medical Journal, vol. 123, no. 6, pp. 292-294, 2005.

[34] K. Izumi, N. Yahagi, Y. Fujii et al., "Cleidocranial dysplasia plus vascular anomalies with 6p21.2 microdeletion spanning RUNX2 and VEGF," American Journal of Medical Genetics Part A, vol. 140, no. 4, pp. 398-401, 2006.

[35] B. A. Fernandez, J. Siegel-Bartelt, J. A. Herbrick, I. Teshima, and S. W. Scherer, "Holoprosencephaly and cleidocranial dysplasia in a patient due to two position-effect mutations: case report and review of the literature," Clinical Genetics, vol. 68, no. 4, pp. 349-359, 2005.

[36] T. Goto, M. Aramaki, H. Yoshihashi et al., "Large fontanelles are a shared feature of haploinsufficiency of RUNX2 and its co-activator CBFB," Congenital Anomalies, vol. 44, no. 4, pp. 225-229, 2004.

[37] A. B. Patel and A. M. Athavale, "Cleidocranial dysplasia," Indian Journal of Pediatrics, vol. 41, no. 6, pp. 622-623, 2004.

[38] I. Golan, U. Baumert, H. Wagener et al., "Atypical expression of cleidocranial dysplasia: clinical and molecular-genetic analysis," Orthodontics and Craniofacial Research, vol. 5, no. 4, pp. 243-249, 2002. 
[39] I. Golan, U. Baumert, P. Held, S. Feuerbach, and D. Müssig, "Radiological findings and molecular genetic confirmation of cleidocranial dysplasia," Clinical Radiology, vol. 57, no. 6, pp. 525-529, 2002.

[40] N. Sakai, H. Hasegawa, Y. Yamazaki et al., "A case of a Japanese patient with cleidocranial dysplasia possessing a mutation of CBFA1 gene," Journal of Craniofacial Surgery, vol. 13, no. 1, pp. 31-34, 2002.

[41] M. F. Madeira, I. M. Caetano, E. Dias-Ribeiro et al., "Orthognathic surgery in patients with cleidocranial dysplasia," Journal of Craniofacial Surgery, vol. 26, no. 3, pp. 792-795, 2015.

[42] C. Y. Zhang, Y. Si, X. Z. Wang, X. Y. Sun, W. J. Yan, and S. G. Zheng, "Early dental treatments for patients with cleidocranial dysplasia," Chinese Journal of Dental Research, vol. 18, no. 1, pp. 51-57, 2015.

[43] S. A. Paul, S. S. Simon, A. K. Karthik, R. K. Chacko, and S. Savitha, "A review of clinical and radiological features of cleidocranial dysplasia with a report of two cases and a dental treatment protocol," Journal of Pharmacy and Bioallied Sciences, vol. 7, no. 6, pp. S428-S432, 2015.

[44] H. Lu, B. Zeng, D. Yu et al., "Complex dental anomalies in a belatedly diagnosed cleidocranial dysplasia patient," Imaging Science in Dentistry, vol. 45, no. 3, pp. 187-192, 2015.

[45] R. Rocha, M. B. Zasso, G. Floriano et al., "Orthodontic traction in a patient with cleidocranial dysplasia: 3 years of follow-up," American Journal of Orthodontics and Dentofacial Orthopedics, vol. 146, no. 1, pp. 108-118, 2014.

[46] T. Chen, J. Hou, L. L. Hu, J. Gao, and B. L. Wu, "A novel small deletion mutation in RUNX2 gene in one Chinese family with cleidocranial dysplasia," International Journal of Clinical and Experimental Pathology, vol. 7, no. 5, pp. 2490-2495, 2014.

[47] A. Hardy, M. W. Thiong'o, A. Leroy, P. Hardy, and C. Laporte, "Cleidocranial dysplasia with bilateral posterior glenohumeral dislocation: a case-report," Orthopaedics \& Traumatology: Surgery \& Research, vol. 101, no. 1, pp. 119-122, 2015.

[48] C. Gömleksiz, E. Arslan, S. Arslan, S. Pusat, and E. A. Arslan, "Delayed diagnosis of cleidocranial dysplasia in an adult: a case report," Acta Medica Academica, vol. 43, no. 1, pp. 92-96, 2014.

[49] M. F. Bedeschi, F. Bonarrigo, F. Manzoni et al., "EhlersDanlos syndrome versus cleidocranial dysplasia," Italian Journal of Pediatrics, vol. 40, no. 1, p. 49, 2014.

[50] S. J. Back and A. N. Pollock, "Cleidocranial dysostosis," Pediatric Emergency Care, vol. 29, no. 7, pp. 867-869, 2013.

[51] R. Vij, P. Batra, and H. Vij, "Cleidocranial dysplasia: complete clinical, radiological and histological profiles," BMJ Case Reports, vol. 20, p. bcr2013009015, 2013.

[52] M. Callea, F. Fattori, I. Yavuz, and E. Bertini, "A new phenotypic variant in cleidocranial dysplasia (CCD) associated with mutation c.391C> T of the RUNX2 gene," BMJ Case Reports, vol. 5, p. bcr1220115422, 2012.

[53] W. R. Nel, S. M. Dawjee, and A. W. van Zyl, "An insight into the malocclusion of cleidocranial dysplasia," $S A D J$, vol. 67, no. 5, pp. 216-220, 2012.

[54] M. T. Sberna, D. De Angelis, F. Laruffa, L. Tettamanti, and E. Storti, "Oral manifestation of cleidocranial displasia," Minerva Stomatologica, vol. 61, no. 10, pp. 421-429, 2012.

[55] C. Mortellaro, A. Greco Lucchina, and E. Prota, "Differing therapeutic approaches to cleidocranial dysplasia (CCD)," Minerva Stomatologica, vol. 61, no. 4, pp. 155-163, 2012.

[56] C. Y. Fang, J. J. Xue, L. Tan et al., "A novel single-base deletion mutation of the RUNX2 gene in a Chinese family with cleidocranial dysplasia," Genetics and Molecular Research, vol. 10, no. 4, pp. 3539-3544, 2011.

[57] V. C. Petropoulos, T. J. Balshi, G. J. Wolfinger, and S. F. Balshi, "Treatment of a patient with cleidocranial dysplasia using a single-stage implant protocol," Journal of Prosthodontics, vol. 20, no. 2, pp. S26-S31, 2011.

[58] D. N. Mehta, R. V. Vachhani, and M. B. Patel, "Cleidocranial dysplasia: a report of two cases," Journal of Indian Society of Pedodontics and Preventive Dentistry, vol. 29, no. 3, pp. 251254, 2011.

[59] M. Trigui, K. Ayadi, M. O. Elhassan, M. Zribi, I. Chabchoub, and H. Keskes, "Cleidocranial dysplasia: report of 2 cases and literature review," Archives de Pédiatrie, vol. 18, no. 6, pp. 672-677, 2011.

[60] D. Dalessandri, L. Laffranchi, I. Tonni et al., "Advantages of cone beam computed tomography (CBCT) in the orthodontic treatment planning of cleidocranial dysplasia patients: a case report," Head and Face Medicine, vol. 7, no. 1, p. 6, 2011.

[61] G. Karagüzel, F. A. Aktürk, E. Okur, H. R. Gümele, Y. Gedik, and A. Okten, "Cleidocranial dysplasia: a case report," Journal of Clinical Research in Pediatric Endocrinology, vol. 2, no. 3, pp. 134-136, 2010.

[62] R. Kamatham, J. Sharada, A. Mohapatra, and S. Nuvvula, "Multiple supernumerary teeth associated with bony malformations," Journal of Clinical Pediatric Dentistry, vol. 36, no. 2, pp. 207-210, 2011.

[63] M. Kamamoto, J. Machida, H. Miyachi et al., "A novel mutation in the C-terminal region of RUNX2/CBFA1 distal to the DNA-binding runt domain in a Japanese patient with cleidocranial dysplasia," International Journal of Oral and Maxillofacial Surgery, vol. 40, no. 4, pp. 434-437, 2011.

[64] D. Xuan, X. Sun, Y. Yan, B. Xie, P. Xu, and J. Zhang, "Effect of cleidocranial dysplasia-related novel mutation of RUNX2 on characteristics of dental pulp cells and tooth development," Journal of Cellular Biochemistry, vol. 111, no. 6, pp. 1473-1481, 2010.

[65] R. P. Mohan, G. N. Suma, S. Vashishth, and S. Goel, "Cleidocranial dysplasia: clinico-radiological illustration of a rare case," Journal of Oral Science, vol. 52, no. 1, pp. 161-166, 2010.

[66] G. X. Wang, R. P. Sun, and F. L. Song, "A novel RUNX2 mutation (T420I) in Chinese patients with cleidocranial dysplasia," Genetics and Molecular Research, vol. 9, no. 1, pp. 41-47, 2010.

[67] A. H. El-Gharbawy, J. N. Peeden Jr., R. S. Lachman, J. M. Graham Jr., S. R. Moore, and D. L. Rimoin, "Severe cleidocranial dysplasia and hypophosphatasia in a child with microdeletion of the C-terminal region of RUNX2," American Journal of Medical Genetics Part A, vol. 152A, no. 1, pp. 169-174, 2010.

[68] P. K. Dhanpal and N. M. King, "Bilateral bimaxillary bi-rooted primary canines: report of a case," Journal of Clinical Pediatric Dentistry, vol. 34, no. 2, pp. 113-116, 2009.

[69] A. Ioscovich, D. Barth, A. Samueloff, S. Grisaru-Granovsky, and S. Halpern, "Anesthetic management of a patient with cleidocranial dysplasia undergoing various obstetric procedures," International Journal of Obstetric Anesthesia, vol. 19, no. 1, pp. 106-108, 2010.

[70] H. T. Chelvan, N. Malathi, V. Kailasam, and A. Ponnudurai, "Cleidocranial dysplasia: a family report," Journal of Indian Society of Pedodontics and Preventive Dentistry, vol. 27, no. 4, pp. 249-252, 2009.

[71] S. S. Suresh, "A family with cleidocranial dysplasia and crossed ectopic kidney in one child," Acta Orthopaedica Belgica, vol. 75, no. 4, pp. 521-527, 2009. 
[72] N. Kang, S. Z. Kim, and S. N. Jung, "Correction of depressed forehead with BoneSource in cleidocranial dysplasia," Journal of Craniofacial Surgery, vol. 20, no. 2, pp. 564-566, 2009.

[73] G. Farronato, C. Maspero, D. Farronato, and S. Gioventù, "Orthodontic treatment in a patient with cleidocranial dysostosis," Angle Orthodontist, vol. 79, no. 1, pp. 178-185, 2009.

[74] S. Rasool, M. H. Sakran, F. Bashir, and S. Gardezi, "Cleidocranial dysplasia in a young girl," Journal of the College of Physicians and Surgeons Pakistan, vol. 18, no. 10, pp. 664-665, 2008.

[75] G. E. Gonzalez, P. A. Caruso, J. E. Small, R. W. Jyung, M. J. Troulis, and H. D. Curtin, "Craniofacial and temporal bone CT findings in cleidocranial dysplasia," Pediatric Radiology, vol. 38, no. 8, pp. 892-897, 2008.

[76] S. M. Purandare, R. Mendoza-Londono, S. A. Yatsenko et al., "De novo three-way chromosome translocation 46,XY,t(4;6; 21)(p16;p21.1;q21) in a male with cleidocranial dysplasia," American Journal of Medical Genetics Part A, vol. 146A, no. 4, pp. 453-458, 2008.

[77] R. Hemalatha and M. R. Balasubramaniam, "Cleidocranial dysplasia: a case report," Journal of Indian Society of Pedodontics and Preventive Dentistry, vol. 26, no. 1, pp. 40-43, 2008.

[78] H. McBrien, J. Turk, and N. Letch, "The management of ADHD and associated problems in a young person with cleidocranial dysostosis (CCD) and mild intellectual disability," Clinical Child Psychology and Psychiatry, vol. 11, no. 3, pp. 445-456, 2006.

[79] S. Tang, Q. Xu, X. Xu et al., "A novel RUNX2 missense mutation predicted to disrupt DNA binding causes cleidocranial dysplasia in a large Chinese family with hyperplastic nails," BMC Medical Genetics, vol. 8, p. 82, 2007.

[80] S. Kobayashi, K. Uchida, H. Baba et al., "Atlantoaxial subluxation-induced myelopathy in cleidocranial dysplasia. Case report," Journal of Neurosurgery: Spine, vol. 7, no. 2, pp. 243-247, 2007.

[81] S. Kuroda, T. Yanagita, H. M. Kyung, and T. TakanoYamamoto, "Titanium screw anchorage for traction of many impacted teeth in a patient with cleidocranial dysplasia," American Journal of Orthodontics and Dentofacial Orthopedics, vol. 131, no. 5, pp. 666-669, 2007.

[82] J. L. Tanaka, E. Ono, E. M. Filho, J. C. Castilho, L. C. Moraes, and M. E. Moraes, "Cleidocranial dysplasia: importance of radiographic images in diagnosis of the condition," Journal of Oral Science, vol. 48, no. 3, pp. 161-166, 2006.

[83] A. Olszewska, "Dental treatment strategies in a 40-year-old patient with cleidocranial dysplasia," Journal of Applied Genetics, vol. 47, no. 2, pp. 199-201, 2006.

[84] V. S. Mohan, R. S. Desai, and M. B. Patil, "Cleidocranial dysplasia with bilateral polycystic ovarian disease and Mullerian abnormality of the uterus: a case report," Journal of Oral Pathology and Medicine, vol. 35, no. 5, pp. 311-313, 2006.

[85] G. Tokuc, P. Boran, and B. O. Boran, "Cleidocranial dysplasia in a mother and her daughter within the scope of neurosurgery. Report of two cases," Journal of Neurosurgery: Pediatrics, vol. 104, no. 4, pp. 290-292, 2006.

[86] Z. Suba, G. Balaton, S. Gyulai-Gaál, P. Balaton, J. Barabás, and I. Tarján, "Cleidocranial dysplasia: diagnostic criteria and combined treatment," Journal of Craniofacial Surgery, vol. 16, no. 6, pp. 1122-1126, 2005.

[87] R. Vakili and F. Jalali, "Hypogonadotropic hypogonadism associated with cleidocranial dysostosis," Journal of Pediatric Endocrinology and Metabolism, vol. 18, no. 9, pp. 917-919, 2005.
[88] A. D. Angle and J. Rebellato, "Dental team management for a patient with cleidocranial dysostosis," American Journal of Orthodontics and Dentofacial Orthopedics, vol. 128, no. 1, pp. 110-117, 2005.

[89] B. S. González López, C. Ortiz Solalinde, T. Kubodera Ito, E. Lara Carrillo, and E. Ortiz Solalinde, "Cleidocranial dysplasia: report of a family," Journal of Oral Science, vol. 46, no. 4, pp. 259-266, 2004.

[90] T. Furuuchi, S. Kochi, T. Sasano, M. Iikubo, S. Komai, and K. Igari, "Morphologic characteristics of masseter muscle in cleidocranial dysplasia: a report of 3 cases," Oral Surgery, Oral Medicine, Oral Pathology, Oral Radiology, and Endodontology, vol. 99, no. 2, pp. 185-190, 2005.

[91] O. Cogulu, D. Munanoglu, E. Karaca, H. Onay, and F. Ozkinay, "Cleidocranial dysplasia with new additional findings," Genetic Counseling, vol. 15, no. 2, pp. 229-231, 2004.

[92] V. C. Petropoulos, T. J. Balshi, S. F. Balshi, and G. J. Wolfinger, "Treatment of a patient with cleidocranial dysplasia using osseointegrated implants: a patient report," International Journal of Oral and Maxillofacial Implants, vol. 19, no. 2, pp. 282-287, 2004.

[93] M. Yildirim, M. Ersoz, F. Alper et al., "Bone scintigraphy in cleidocranial dysplasia," Clinical Nuclear Medicine, vol. 29, no. 1, pp. 65-67, 2004.

[94] S. Unger, E. Mornet, S. Mundlos, S. Blaser, and D. E. Cole, "Severe cleidocranial dysplasia can mimic hypophosphatasia," European Journal of Pediatrics, vol. 161, no. 11, pp. 623-626, 2002.

[95] E. Morava, J. Kárteszi, J. Weisenbach, A. Caliebe, S. Mundlos, and K. Méhes, "Cleidocranial dysplasia with decreased bone density and biochemical findings of hypophosphatasia," European Journal of Pediatrics, vol. 161, no. 11, pp. 619-622, 2002.

[96] L. Machuca-Tzili, N. Monroy-Jaramillo, A. González-del Angel, and S. Kofman-Alfaro, "New mutations in the CBFA1 gene in two Mexican patients with cleidocranial dysplasia," Clinical Genetics, vol. 61, no. 5, pp. 349-353, 2002.

[97] A. Björk, "Sutural growth of the upper face studied by the implant method," European Journal of Orthodontics, vol. 29, no. 1, pp. i82-i88, 2997.

[98] H. Wehrbein and P. Göllner, "Skeletal anchorage in orthodontics-basics and clinical application," Journal of Orofacial Orthopedics, vol. 68, no. 6, pp. 443-461, 2007. 


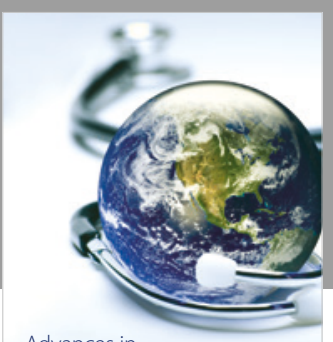

Advances in
Public Health

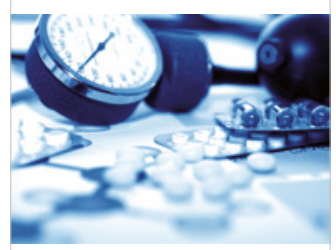

Case Reports in

Medicine

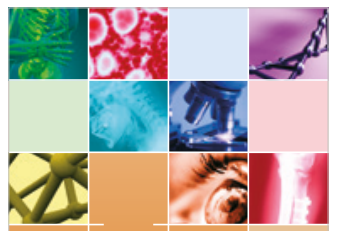

niernational Journal of

Biomaterials
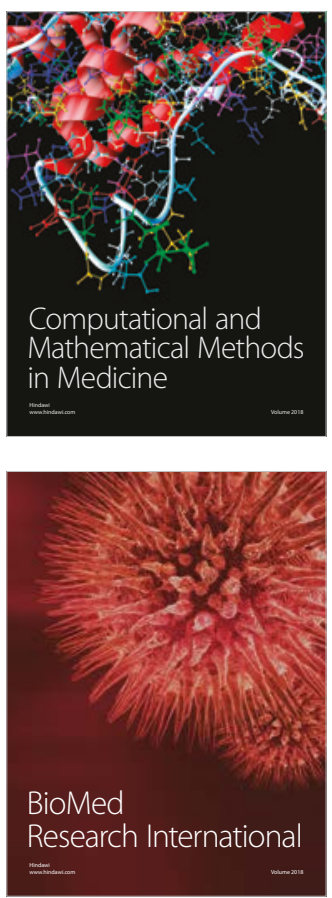

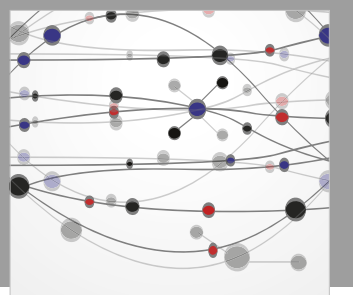

The Scientific World Journal Dentistry

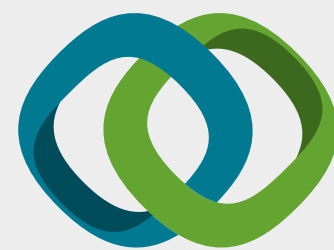

Hindawi

Submit your manuscripts at

www.hindawi.com
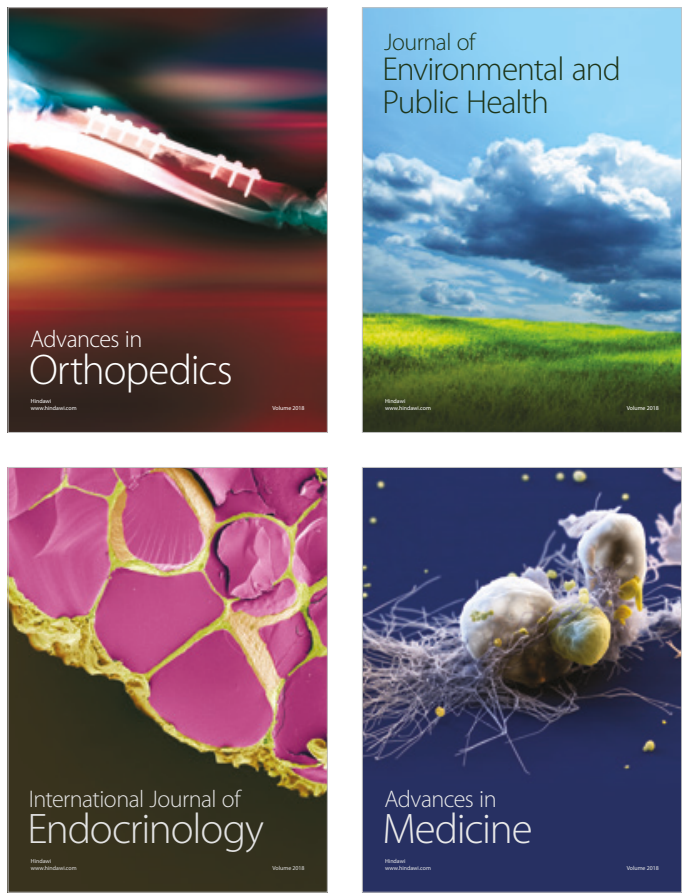
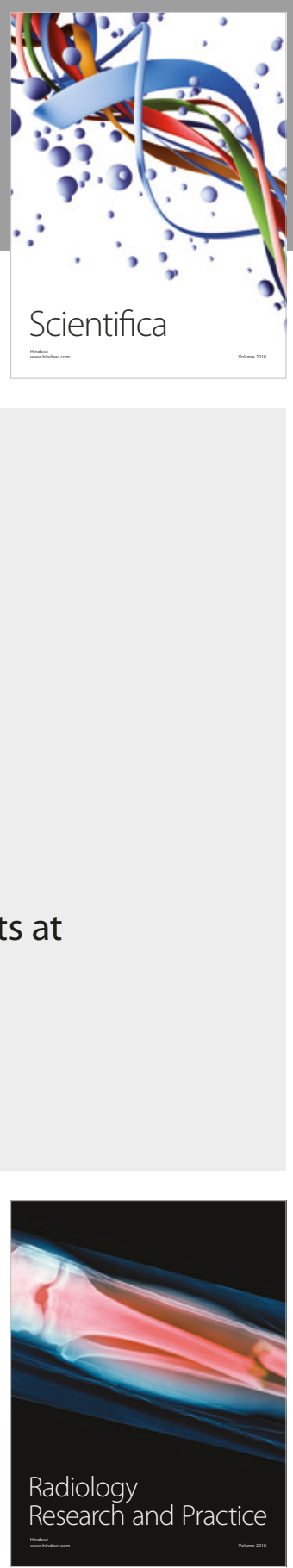

Scientifica

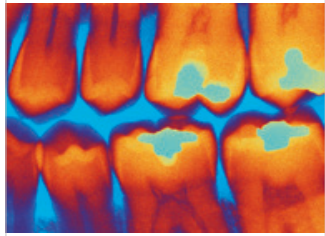

Case Reports in

Dentistry
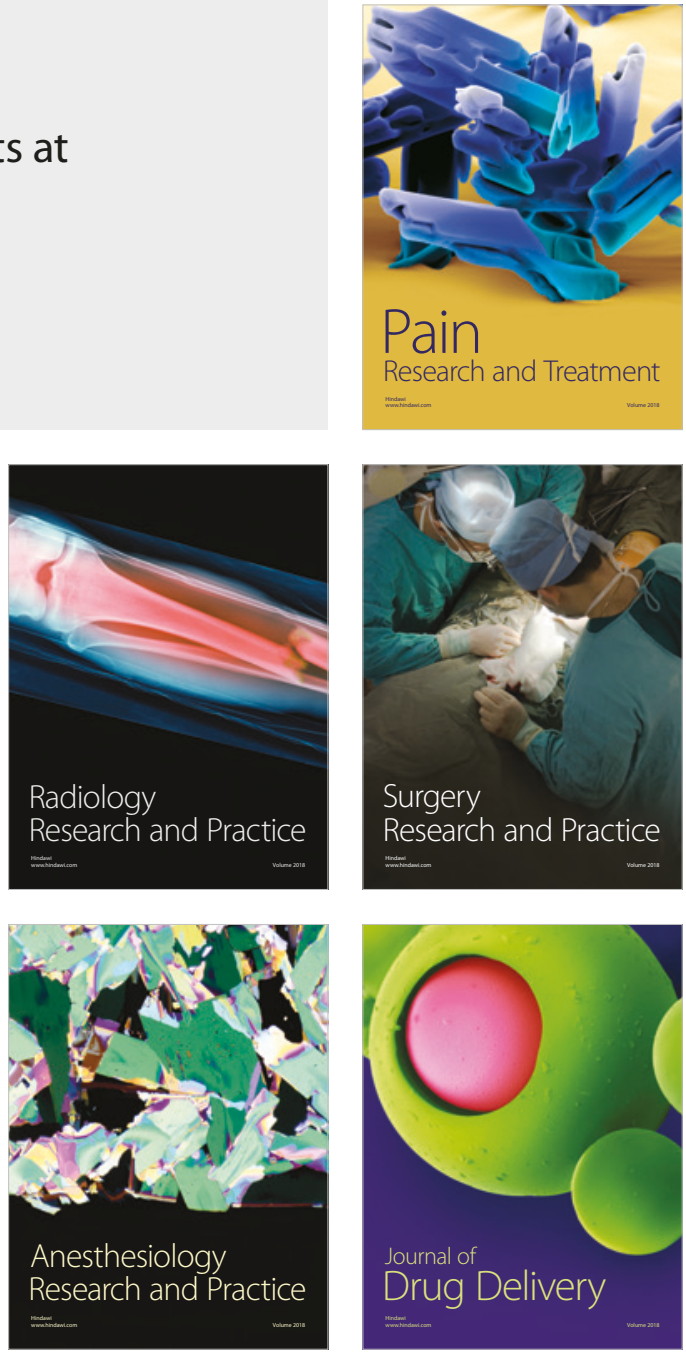